\title{
Cloud radar with hybrid mode towards estimation of shape and orientation of ice crystals
}

\author{
A. Myagkov ${ }^{1}$, P. Seifert ${ }^{1}$, M. Bauer-Pfundstein ${ }^{2}$, and U. Wandinger ${ }^{1}$ \\ ${ }^{1}$ Leibniz Institute for Tropospheric Research (TROPOS), Permoserstr. 15, 04318 Leipzig, Germany \\ ${ }^{2}$ METEK Meteorologische Messtechnik GmbH, Fritz-Straßmann-Str. 4, 25337 Elmshorn, Germany \\ Correspondence to: A. Myagkov (myagkov@ tropos.de)
}

Received: 20 July 2015 - Published in Atmos. Meas. Tech. Discuss.: 3 September 2015

Revised: 28 December 2015 - Accepted: 11 January 2016 - Published: 12 February 2016

\begin{abstract}
This paper is devoted to the experimental quantitative characterization of the shape and orientation distribution of ice particles in clouds. The characterization is based on measured and modeled elevation dependencies of the polarimetric parameters differential reflectivity and correlation coefficient. The polarimetric data are obtained using a newly developed $35 \mathrm{GHz}$ cloud radar MIRA-35 with hybrid polarimetric configuration and scanning capabilities. The full procedure chain of the technical implementation and the realization of the setup of the hybrid-mode cloud radar for the shape determination are presented. This includes the description of phase adjustments in the transmitting paths, the introduction of the general data processing scheme, correction of the data for the differences of amplifications and electrical path lengths in the transmitting and receiving channels, the rotation of the polarization basis by $45^{\circ}$, the correction of antenna effects on polarimetric measurements, the determination of spectral polarimetric variables, and the formulation of a scheme to increase the signal-to-noise ratio. Modeling of the polarimetric variables is based on existing backscattering models assuming the spheroidal representation of cloud scatterers. The parameters retrieved from the model are polarizability ratio and degree of orientation, which can be assigned to certain particle orientations and shapes. The developed algorithm is applied to a measurement of the hybridmode cloud radar taken on 20 October 2014 in Cabauw, the Netherlands, in the framework of the ACCEPT (Analysis of the Composition of Clouds with Extended Polarization Techniques) campaign. The case study shows the retrieved polarizability ratio and degree of orientation of ice particles for a cloud system of three cloud layers at different heights. Retrieved polarizability ratios are $0.43,0.85$, and 1.5 which cor-
\end{abstract}

respond to oblate, quasi-spherical, and columnar ice particles, respectively. It is shown that the polarizability ratio is useful for the detection of aggregation/riming processes. The orientation of oblate and prolate particles is estimated to be close to horizontal while quasi-spherical particles were found to be more randomly oriented.

\section{Introduction}

The continuous observation of ice-crystal habit is a key component for an improved characterization of mixed-phase clouds with remote-sensing techniques (Shupe et al., 2008). De Boer et al. (2009) considered the shape of ice particles to be the largest source of errors in existing size and number concentration retrievals that are based on combined lidar and radar vertical observations. For instance, the authors reported that the assumed ice particle shape can cause changes in the calculated effective size and number concentration of up to $200 \mu \mathrm{m}$ and $90 \mathrm{~L}^{-1}$, respectively. In existing microphysical models, an accurate representation of ice particle shape plays an important role as the shape parameterizes sizemass-terminal velocity relations of the ice phase (Mitchell, 1996; Delanoë et al., 2014), the depositional growth rate (Westbrook and Heymsfield, 2011), and scattering properties of the ice crystals (Delanoë and Hogan, 2010). Moreover, knowledge of the ice particles' shape provides a potential for the retrieval of the particle number size distribution. Such a retrieval can be based on the cloud radar Doppler spectra and known relations between size and terminal velocity for different particle habits (Mitchell, 1996). Mace et al. (2002) presented a retrieval of the number size distribution based 
on the moments of Doppler spectra obtained with a $35 \mathrm{GHz}$ cloud radar. The authors estimated the uncertainties of the retrieval associated with the ice particle habit and found those to be 60 and $40 \%$ in ice water content and median ice particle size, respectively. Continuous information about the number size distribution of ice particles can later on be helpful for a better understanding and characterization of the efficiency of heterogeneous ice formation, which currently is subject of numerous studies (Hoose and Möhler, 2012; Murray et al., 2012; Phillips et al., 2013; Ladino Moreno et al., 2013; DeMott et al., 2015).

Cloud radar is one of the most promising remote-sensing instruments for particle shape determination. Recent investigations of Kneifel et al. (2011, 2015) show the potential of the multi-frequency approach in the separation of snow particle habits when Mie scattering is present. According to Kneifel et al. (2015), the approach is most effective for a median volume diameter exceeding $2 \mathrm{~mm}$. Often, characterization of smaller ice crystals is required. For example, in midlevel mixed-phase clouds the typical size of ice crystals is about an order of magnitude lower.

Another powerful tool for the shape estimation of cloud particles is cloud-radar polarimetry. The polarimetric approach is known to be effective in the case when cloud particles can be approximated using the well-known spheroidal model (Holt, 1984). Matrosov (1991a) presented theoretical considerations about the potential of polarimetric cloud radars for the shape classification of ice crystals. The author analyzed modeled elevation dependencies of polarimetric products that could be measured with several polarimetric configurations. Matrosov and Kropfli (1993), Matrosov et al. (2001), and Reinking et al. (2002) experimentally evaluated the proposed polarimetric configurations that were emulated using rotatable quarter- and/or half-wavelength phase plates. The plates were mounted into the waveguide system of a ground-based Ka-band radar, operated by the Wave Propagation Laboratory of the National Oceanic and Atmospheric Administration. A number of studies present polarimetric measurements of winter clouds taken by airborne (Galloway et al., 1997; Wolde and Vali, 2001) and groundbased cloud radars (Pazmany et al., 1994; Lohmeier et al., 1997; Reinking et al., 2002). Often such measurements were compared with the microphysical properties of the ice crystals observed in situ with aircraft or on ground. Despite the observational evidence that polarimetric variables are sensitive to the shape of particles, which was confirmed by the above-mentioned studies, further investigations in this area are required to realize an operational quantitative characterization of particle shape (Matrosov et al., 2012). An approach to quantitatively obtain the particle shape and orientation from weather radar observations of polarimetric parameters was, e.g., presented by Melnikov and Straka (2013), but their retrieval has limitations in the discrimination between oblate and prolate particles.
Even though the potential of different polarimetric configurations for a detailed shape retrieval of hydrometeors were evaluated in the above-mentioned studies, many cloud radars are operated in simpler configurations. The widely used spaceborne $94 \mathrm{GHz}$ cloud profiling radar aboard the CloudSat satellite has no polarization capabilities at all (Stephens et al., 2008). Other systems operate in a depolarization mode (also known as polarization diverse mode). In this mode the radar emits a wave with a certain constant polarization state (usually linear or circular) and receives co-polarized and cross-polarized components of the backscattered wave. This is, e.g., the case for the default setup of MIRA-35 (Görsdorf et al., 2015) as well as the Ka-band Zenith-pointing Radar (KAZR) of the US Department of Energy (DoE) Atmospheric Radiation Measurement (ARM) program. Normally such radars provide only one polarimetric product the depolarization ratio - which is the ratio of the returned power in the cross-polarized channel to the returned power in the co-polarized channel. If only the depolarization ratio is used to derive an estimate of ice particle shape, an assumption about the distribution of ice crystal orientation has to be made as described in Matrosov et al. (2001). Ryzhkov (2001) concluded that not only power relations but also the correlation between the orthogonal components of the received wave should be analyzed for the characterization of both shape and orientation distribution.

In this paper we propose an approach to simultaneously estimate the shape and orientation of ice particles. The algorithm utilizes elevation dependencies of differential reflectivity $Z_{\mathrm{DR}}$ and correlation coefficient $\rho_{\mathrm{HV}}$ that are related to the output of a spheroidal scattering model. The method is applied to polarimetric observations obtained with a new modification of the scanning $35 \mathrm{GHz}$ cloud radar of type MIRA-35 with hybrid polarimetric configuration.

The paper is organized as follows. Section 2 contains the description of the technical implementation of the hybrid mode in the cloud radar, calibration issues, and processing considerations. The approach for the retrieval of the shape and orientation distribution is presented in Sect. 3. A case study showing the application of the method is given in Sect. 4. Conclusions and further considerations are presented in Sect. 5.

\section{MIRA-35 with hybrid mode}

MIRA-35 is a magnetron-based $35 \mathrm{GHz}$ cloud radar produced by METEK GmbH, Elmshorn, Germany. Several measurement sites in Europe operate radars of this type in the framework of Cloudnet, which is part of the Aerosols, Clouds and Trace gases Research Infrastructure (ACTRIS), because of their high sensitivity and reliability (Illingworth et al., 2007; Martucci and O'Dowd, 2011; Di Girolamo et al., 2012; Bühl et al., 2013; Löhnert et al., 2015). Görsdorf et al. (2015) describe the technical implementation of MIRA-35, accuracy 
Table 1. Parameters of MIRA-35 used in the operational mode.

\begin{tabular}{lr}
\hline Peak power $(\mathrm{kW})$ & 30 \\
Beam width for $1 \mathrm{~m}$ antenna $\left({ }^{\circ}\right)$ & 0.6 \\
Pulse length $(\mathrm{ns})$ & 200 \\
Pulse repetition frequency $(\mathrm{kHz})$ & 5 \\
Minimum range $(\mathrm{km})$ & 0.15 \\
Maximum range $(\mathrm{km})$ & 15 \\
Range resolution $(\mathrm{m})$ & 30 \\
Number of pulses for fast Fourier transform (FFT) & 256 \\
Number of spectra for averaging & 200 \\
Sensitivity at $5 \mathrm{~km}(\mathrm{dBZ})$ & -55
\end{tabular}

issues, and operational statistics based on more than 10 years of continuous measurements. Recently, a MIRA-35 was installed on board the research aircraft HALO (Mech et al., 2014). Main operational parameters of MIRA-35 are listed in Table 1.

Typically, cloud radars of type MIRA-35 emit linearly polarized waves. The corresponding operation mode is denoted as the linear depolarization ratio mode (LDR mode). Often, LDR measurements taken with vertically pointed cloud radars are used for clutter filtering (Görsdorf et al., 2015) and a reliable detection of the melting layer (Lohmeier et al., 1997). At the same time the applicability of the LDR mode for the shape estimation is limited because of its high sensitivity to the orientation of cloud particles (Matrosov et al., 2001).

For the shape studies presented in this paper we used the hybrid mode. This mode is also known as the Simultaneous Transmission and Simultaneous Reception (STSR) mode and is often used in weather radars (Ryzhkov et al., 2005). In hybrid mode a radar transmits horizontal and vertical components of the signal simultaneously; thus, expensive highpulse-power polarization switching is not required. As will be shown below, the hybrid mode is capable of providing polarimetric parameters that allow for a quantitative estimate of particles shape and orientation characteristics.

This section is devoted to the technical realization, calibration, and the data processing of the new hybrid-mode radar. In Sect. 2.1 we present the implementation of the horizontal and vertical channel of the radar and describe the phase adjustment procedure. An overview of the general data processing is given in Sect. 2.2. The correction of the data for the differences of amplifications and electrical path lengths in the horizontal and vertical channel is described in Sect. 2.3. The representation of the measured data in a $45^{\circ}$ rotated polarization basis, which permits the depolarization ratio to be retrieved, is presented in Sect. 2.4. In Sect. 2.5 it is explained how antenna effects on polarimetric measurements are corrected. The spectral polarimetric variables are derived in Sect. 2.6. The applied approach to increase the signal-tonoise ratio in the hybrid mode is presented in Sect. 2.7. पa $\square$ Standard configuration of MIRA-35 (LDR mode)

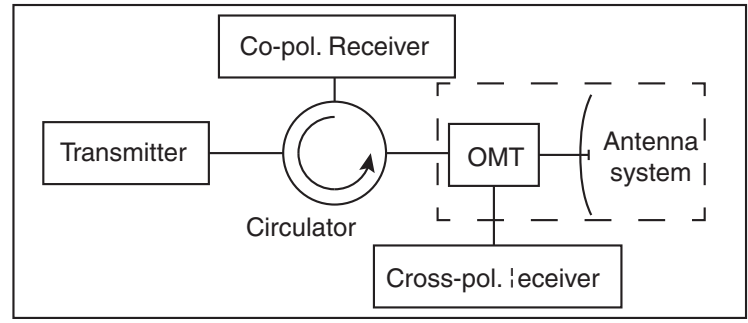

Gb $\square$ MIRA-35 with the hybrid mode

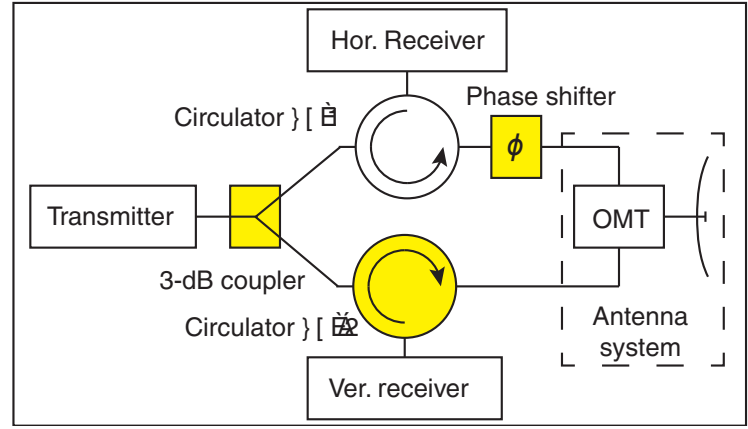

Figure 1. Simplified block diagrams of typical LDR (a) and hybrid (b) modes of MIRA-35. Components, added for the implementation of the hybrid mode from the LDR mode, are shown in yellow color. OMT is an orthomode transducer. See details in the text.

\subsection{Implementation and phase adjustment}

The implementation of the hybrid mode was based on a standard scanning MIRA-35 cloud radar configured for the LDR mode. Simplified schemes of traditional LDR mode and the implemented hybrid configuration are shown in Fig. 1. In the hybrid mode, high-frequency power, generated by the magnetron-based transmitter, is split into two channels by a $3 \mathrm{~dB}$ coupler. A second circulator is added to decouple the high-power transmission line from the sensitive receiver in the vertical channel. Note that here we only show changes that were implemented in order to realize the hybrid mode. Details about the standard LDR configuration can be found in Görsdorf et al. (2015).

It is known that the exact polarization state of the transmitted radiation depends on the phase shift between the orthogonal components of the transmitted signal $\Delta \varphi_{\mathrm{T}}$ (transmission phase difference). Often, polarimetric weather radars use an arbitrary elliptical polarization as the transmission phase difference $\Delta \varphi_{\mathrm{T}}$ is not adjusted to a certain value. We decided to first evaluate the hybrid mode with the transmission phase difference $\Delta \varphi_{\mathrm{T}}$ adjusted to $0^{\circ}$, i.e., linear polarization of the transmitted radiation. In the future a circular or elliptical polarization state of the transmitted signal can be easily implemented by shifting $\Delta \varphi_{\mathrm{T}}$. Adjustable ferrite phase shifters for the peak power of $15 \mathrm{~kW}$ at Ka-band are expensive and, in addition, introduce extra power losses which will result in worse sensitivity. Instead, in order to adjust the phase shift, 


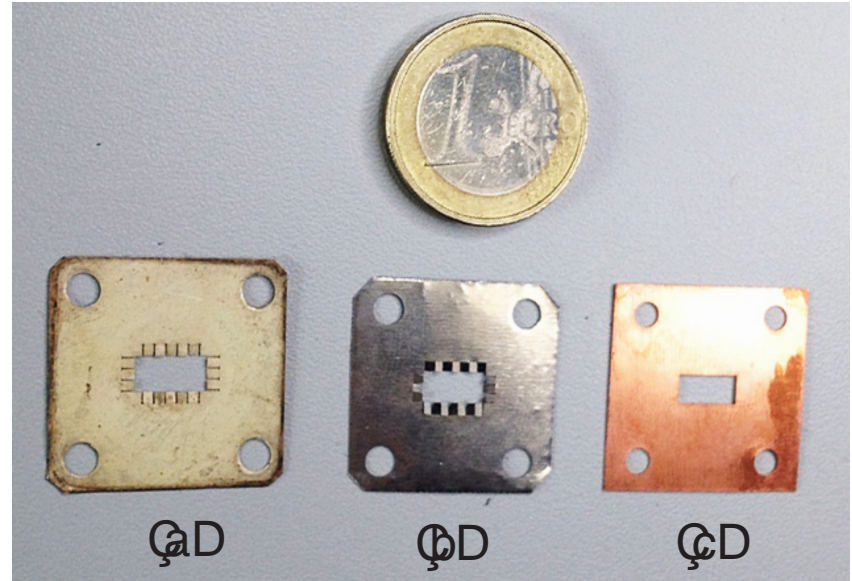

Figure 2. Throttle plates used for the phase adjustment. The thickness of the plates is $0.05 \mathrm{~mm}(\mathbf{a}), 0.1 \mathrm{~mm}(\mathbf{b})$, and $0.28 \mathrm{~mm}$ (c). The introduced phase shift is $1.8^{\circ}(\mathbf{a}), 3.4^{\circ}(\mathbf{b})$, and $9.1^{\circ}$ (c).

we slightly changed the path length of the horizontal channel by inserting throttle plates (Fig. 2) between the waveguide flanges. Changing of the transmission phase shift $\Delta \varphi_{\mathrm{T}}$ requires throttle plates to be inserted right after the $3 \mathrm{~dB}$ coupler. In MIRA-35 the $3 \mathrm{~dB}$ coupler is installed inside the receiver unit and cannot be easily reached. Thus, due to the construction design of MIRA-35 we inserted throttle plates after the circulator no. 1 (see Fig. 1b). Introducing the additional phase shift after the circulator leads to changes of the phase shift induced in the receiving paths $\Delta \varphi_{\mathrm{R}}$ (reception phase difference). The reception phase difference $\Delta \varphi_{\mathrm{R}}$ can be removed during processing (Sect. 2.3).

To characterize phase shifts induced by the radar hardware, a polarization basis should be defined. For the description we use the Cartesian polarization basis $\left(\boldsymbol{e}_{x} \boldsymbol{e}_{y}\right)$, shown in Fig. 3, throughout the paper. In the description basis, the total phase difference between the horizontal and vertical channels $\Delta \varphi_{\Sigma}$ measured in the configuration shown in Fig. $1 \mathrm{~b}$ can be represented as follows:

$$
\Delta \varphi_{\Sigma}=\varphi_{x}-\varphi_{y}=\underbrace{\Delta \varphi_{\mathrm{tp}}+\Delta \varphi_{\mathrm{ps}}}_{\Delta \varphi_{\mathrm{T}}}+\Delta \varphi_{\mathrm{bs}}+\underbrace{\Delta \varphi_{\mathrm{rp}}+\Delta \varphi_{\mathrm{ps}}}_{\Delta \varphi_{\mathrm{R}}},
$$

where $\varphi_{x}$ and $\varphi_{y}$ are the phases of the signals in the horizontal and vertical channel, respectively, $\Delta \varphi_{\mathrm{tp}}$ is the phase shift caused by the difference in the electrical path lengths between the transmission channels, $\Delta \varphi_{\mathrm{ps}}$ is the phase shift introduced by the phase shifter, $\Delta \varphi_{\mathrm{bs}}$ is the phase shift produced by atmospheric scatterers, and $\Delta \varphi_{\mathrm{rp}}$ is the phase shift caused by differences in the electrical path lengths of the reception channels.

We measured the phase shift $\Delta \varphi_{\mathrm{rp}}$ based on previously documented antenna measurements (Myagkov et al., 2015). For the measurements an external test transmitter was used. The test transmitter generates continuous linearly polarized radiation. The frequency of the test transmitter was set close

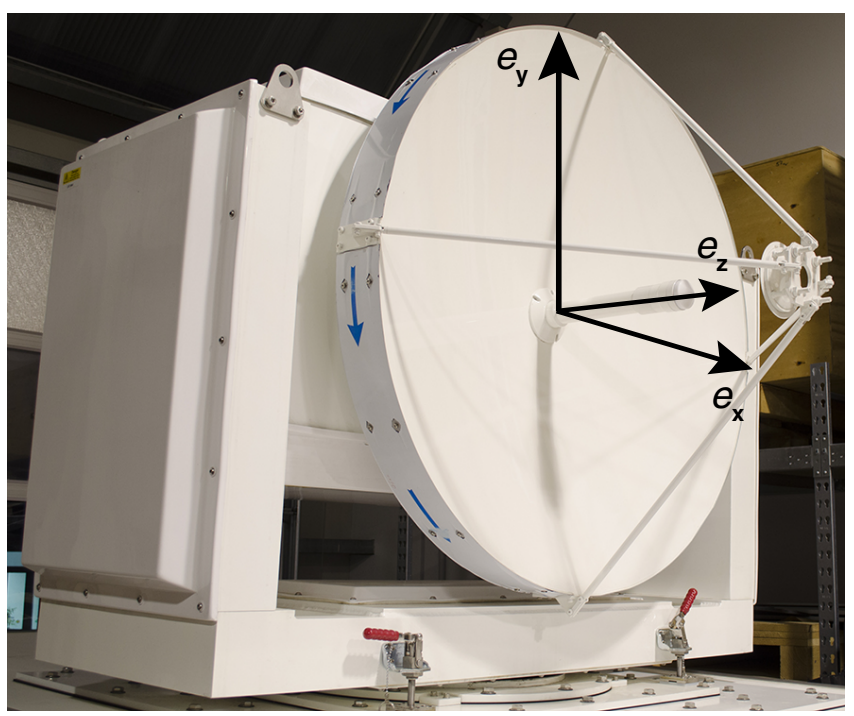

Figure 3. Antenna of MIRA-35 system mounted on the scanning unit. The description polarization basis is shown. The unit vector $\boldsymbol{e}_{z}$ shows the propagation direction of the transmitted radiation.

to the operational frequency of the radar transmitter. The frequency of the radar local oscillator was adjusted to center the receiver bandwidth to the signal of the test transmitter. The rotatable antenna system of the test transmitter permits the orientation $\beta$ of the transmitted polarization to be changed with respect to the unit vector $\boldsymbol{e}_{x}$ of the description basis. The radar was placed approximately $40 \mathrm{~m}$ away from the test transmitter. The radar was operated in the receivingonly mode. Antennas of the radar and the test transmitter were pointed to each other. A detailed description of the test transmitter and the measurement procedure can be found in Myagkov et al. (2015). Measurements conducted at $\beta=45^{\circ}$ showed $\Delta \varphi_{\text {rp }}$ (denoted as $\alpha_{3}(0,0)$ in Myagkov et al., 2015) to be $-2^{\circ}$. Note that these measurements were performed before introducing throttle plates.

Knowing $\Delta \varphi_{\mathrm{rp}}$, we added throttle plates into the horizontal channel in order to measure the introduced phase shift. Plates (Fig. 2) with thickness of $0.28,0.1$, and $0.05 \mathrm{~mm}$ introduced a phase shift of $9.1,3.4$, and $1.8^{\circ}$, respectively. It should be noted that the wavelength in the waveguide $\lambda_{g}$ is $10.8 \mathrm{~mm}$ which is longer than the one in vacuum (Marcuvitz, 1965, Sect. 2.2). Calculated values of $\Delta \varphi_{\mathrm{ps}}$ for $\lambda_{g}$ are $9.3,3.3$, and $1.7^{\circ}$, respectively.

It is known that randomly oriented particles do not produce a backscattering differential phase shift (Trömel et al., 2013). Therefore, for vertical observations of clouds we can assume $\Delta \varphi_{\mathrm{bs}}=0$. In this case $\Delta \varphi_{\mathrm{tp}}$ can be estimated from the measured total phase difference $\Delta \varphi_{\Sigma}$ observed by the vertically pointed radar using Eq. (1). Measurements performed without installed throttle plates resulted in $\Delta \varphi_{\Sigma}=-21.6^{\circ}$ and, thus, $\Delta \varphi_{\mathrm{tp}}=-19.6^{\circ}$. In order to adjust the transmission phase difference $\Delta \varphi_{\mathrm{T}}$ as close to $0^{\circ}$ as possible we 
inserted throttle plates with a total thickness of $\sim 0.6 \mathrm{~mm}$ into the horizontal channel. This introduced $20.5^{\circ}$ of additional phase shift $\Delta \varphi_{\mathrm{ps}}$ and resulted in the transmission phase difference $\Delta \varphi_{\mathrm{T}}=-0.9^{\circ}$ and the reception phase difference $\Delta \varphi_{\mathrm{R}}=18.5^{\circ}$.

During the operation the frequency of the magnetron can vary with temperature within $\pm 1 \mathrm{MHz}$. Such variations of the operational frequency causes changes of $\Delta \varphi_{\Sigma}$. Measured changes of $\Delta \varphi_{\Sigma}$ due to the frequency variation of the magnetron do not exceed $\pm 1^{\circ}$, which can be considered as not significant. Nevertheless, during the operation we have found that variations in ambient conditions can lead to changes of $\pm 8^{\circ}$ in $\Delta \varphi_{\mathrm{rp}}$. Significant changes in $\Delta \varphi_{\mathrm{rp}}$ usually took several days. We do not consider reasons for the $\Delta \varphi_{\text {rp }}$ variations in this paper. To account for these changes, periodical vertical observations in light rain are required. Assuming $\Delta \varphi_{\mathrm{tp}}$ and $\Delta \varphi_{\mathrm{ps}}$ to be constant $\Delta \varphi_{\mathrm{rp}}$ can be found using Eq. (1).

\subsection{Processing of the coherency matrix}

MIRA-35 is a coherent cloud radar. Two receivers calculate in-phase $(I)$ and quadrature $(Q)$ parts for the vertical and horizontal components of the returned signal. Further we denote the horizontal and vertical component by indexes $\mathrm{h}$ and $\mathrm{v}$, respectively. $I_{\mathrm{h}}, I_{\mathrm{v}}, Q_{\mathrm{h}}$, and $Q_{\mathrm{v}}$ components are obtained for every pulse cycle and range gate. Fast Fourier transformation (FFT) over $I_{\mathrm{h}}+i Q_{\mathrm{h}}$ and $I_{\mathrm{v}}+i Q_{\mathrm{v}}$, calculated from $N_{\mathrm{F}}$ pulses, is used to estimate discrete complex spectra $\dot{S}_{\mathrm{h}}\left(\omega_{k}\right)$ and $\dot{S}_{\mathrm{V}}\left(\omega_{k}\right)$, respectively. Here $\omega_{k}$ denotes a Doppler frequency of a spectral component $k=0, \ldots, N_{\mathrm{F}}-1$ :

$\omega_{k}=\frac{k f_{\mathrm{r}} \pi}{N_{\mathrm{F}}}$,

where $f_{\mathrm{r}}$ is the pulse repetition frequency. Details of the $I / Q$ and spectrum computation in MIRA-35 data processing are given by Görsdorf et al. (2015).

Using $N_{\mathrm{s}}$ complex spectra $\dot{S}_{\mathrm{h}}\left(\omega_{k}\right)$ and $\dot{S}_{\mathrm{V}}\left(\omega_{k}\right)$, the spectral form of the $2 \times 2$ coherency matrix can be calculated as follows:

$\mathbf{B}\left(\omega_{k}\right)=\left(\begin{array}{ll}B_{\mathrm{hh}}\left(\omega_{k}\right) & \dot{B}_{\mathrm{hv}}\left(\omega_{k}\right) \\ \dot{B}_{\mathrm{vh}}\left(\omega_{k}\right) & B_{\mathrm{vv}}\left(\omega_{k}\right)\end{array}\right)$.

The elements of the coherency matrix $\mathbf{B}\left(\omega_{k}\right)$ are calculated as follows:

$$
\begin{aligned}
& B_{\mathrm{hh}}\left(\omega_{k}\right)=\left\langle\dot{S}_{\mathrm{h}}\left(\omega_{k}\right) \dot{S}_{\mathrm{h}}^{*}\left(\omega_{k}\right)\right\rangle, \\
& \dot{B}_{\mathrm{hv}}\left(\omega_{k}\right)=\left\langle\dot{S}_{\mathrm{h}}\left(\omega_{k}\right) \dot{S}_{\mathrm{v}}^{*}\left(\omega_{k}\right)\right\rangle, \\
& \dot{B}_{\mathrm{vh}}\left(\omega_{k}\right)=\left\langle\dot{S}_{\mathrm{v}}\left(\omega_{k}\right) \dot{S}_{\mathrm{h}}^{*}\left(\omega_{k}\right)\right\rangle, \\
& B_{\mathrm{vv}}\left(\omega_{k}\right)=\left\langle\dot{S}_{\mathrm{v}}\left(\omega_{k}\right) \dot{S}_{\mathrm{v}}^{*}\left(\omega_{k}\right)\right\rangle,
\end{aligned}
$$

where $^{*}$ is the complex conjugation sign and \langle\rangle denotes averaging over $N_{\mathrm{s}}$ spectra. The real elements $B_{\mathrm{hh}}\left(\omega_{k}\right)$ and
$B_{\mathrm{vv}}\left(\omega_{k}\right)$ are the power spectra in the horizontal and vertical channels, respectively. In MIRA-35 with the LDR mode these spectra represent co- and cross-polarized components of the received signal, respectively, and are used for the calculation of the radar reflectivity factor at horizontal polarization $Z_{\mathrm{h}}$, mean Doppler velocity, Doppler width, and LDR (Görsdorf et al., 2015).

A recent modification of the MIRA-35 software permits one to additionally calculate and store the complex element $\dot{B}_{\mathrm{hv}}\left(\omega_{k}\right)$. It is necessary to note that $\dot{B}_{\mathrm{hv}}\left(\omega_{k}\right)=\dot{B}_{\mathrm{vh}}^{*}\left(\omega_{k}\right)$. Therefore, storage of the element $\dot{B}_{\mathrm{vh}}\left(\omega_{k}\right)$ is not required. Storing the elements $B_{\mathrm{hh}}\left(\omega_{k}\right), \dot{B}_{\mathrm{hv}}\left(\omega_{k}\right)$, and $B_{\mathrm{vv}}\left(\omega_{k}\right)$ in usual operational mode (Table 1 ) requires approximately $700 \mathrm{MBh}^{-1}$ which is about 100 times less than storing the $I / Q$ data.

\subsection{Correction of the coherency matrix for differences of channels}

The spectral form of the coherency matrix $\mathbf{B}\left(\omega_{k}\right)$ allows for the calculation of spectral polarimetric variables. Advantages of such a representation have been shown for weather radar applications (Spek et al., 2008). Before the calculation of polarimetric parameters the elements of the coherency matrix $\mathbf{B}\left(\omega_{k}\right)$ were corrected for the effect of differential amplification in the horizontal and vertical channels. We define the spectral components $\omega_{n}(n \in k)$ where both $B_{\mathrm{hh}}\left(\omega_{k}\right)$ and $B_{\mathrm{vv}}\left(\omega_{k}\right)$ are at least $30 \mathrm{~dB}$ higher than the mean noise levels $N_{\mathrm{h}}$ and $N_{\mathrm{v}}$, respectively. The mean noise levels in this paper represent a noise level in a spectral line and can be determined by averaging the power spectra over the last range gates where no scatterers are present or by applying the Hildebrand-Sekhon algorithm (Hildebrand and Sekhon, 1974).

In order to correct the difference in the amplifications we calculate a coefficient $K_{\mathrm{a}}$ :

$K_{\mathrm{a}}=\frac{B_{\mathrm{hh}}\left(\omega_{n}\right)-N_{\mathrm{h}}}{B_{\mathrm{vv}}\left(\omega_{n}\right)-N_{\mathrm{v}}}$.

Note that $N_{\mathrm{h}}$ and $N_{\mathrm{v}}$ in Eq. (8) can be neglected because of high signal-to-noise ratios (SNRs) of signals used. For the calculation of $K_{\mathrm{a}}$ we used rain observations with the vertically pointed radar. In this case particles can be considered as spheres and do not change the polarization of the scattered wave. Data containing scattering from insects, that typically cause depolarization, should be avoided. For a rain event on 1 May 2014 we measured a $K_{\mathrm{a}}$ value of $1.46 \pm 0.02$.

The effect of differences in the amplifications and the electrical path lengths on the components of Eq. (3) can be corrected as follows:

$\dot{B}_{\mathrm{hv}}^{\prime}\left(\omega_{k}\right)=\sqrt{K_{\mathrm{a}}} \dot{B}_{\mathrm{hv}}\left(\omega_{k}\right) e^{-i \Delta \varphi_{\mathrm{R}}}$,

$B_{\mathrm{vv}}^{\prime}\left(\omega_{k}\right)=K_{\mathrm{a}} B_{\mathrm{vv}}\left(\omega_{k}\right)$.

The additional phase shift, introduced in $\dot{B}_{\mathrm{hv}}^{\prime}\left(\omega_{k}\right)$, removes the reception phase difference $\Delta \varphi_{\mathrm{R}}$. The spectra $B_{\mathrm{hh}}\left(\omega_{k}\right)$, 

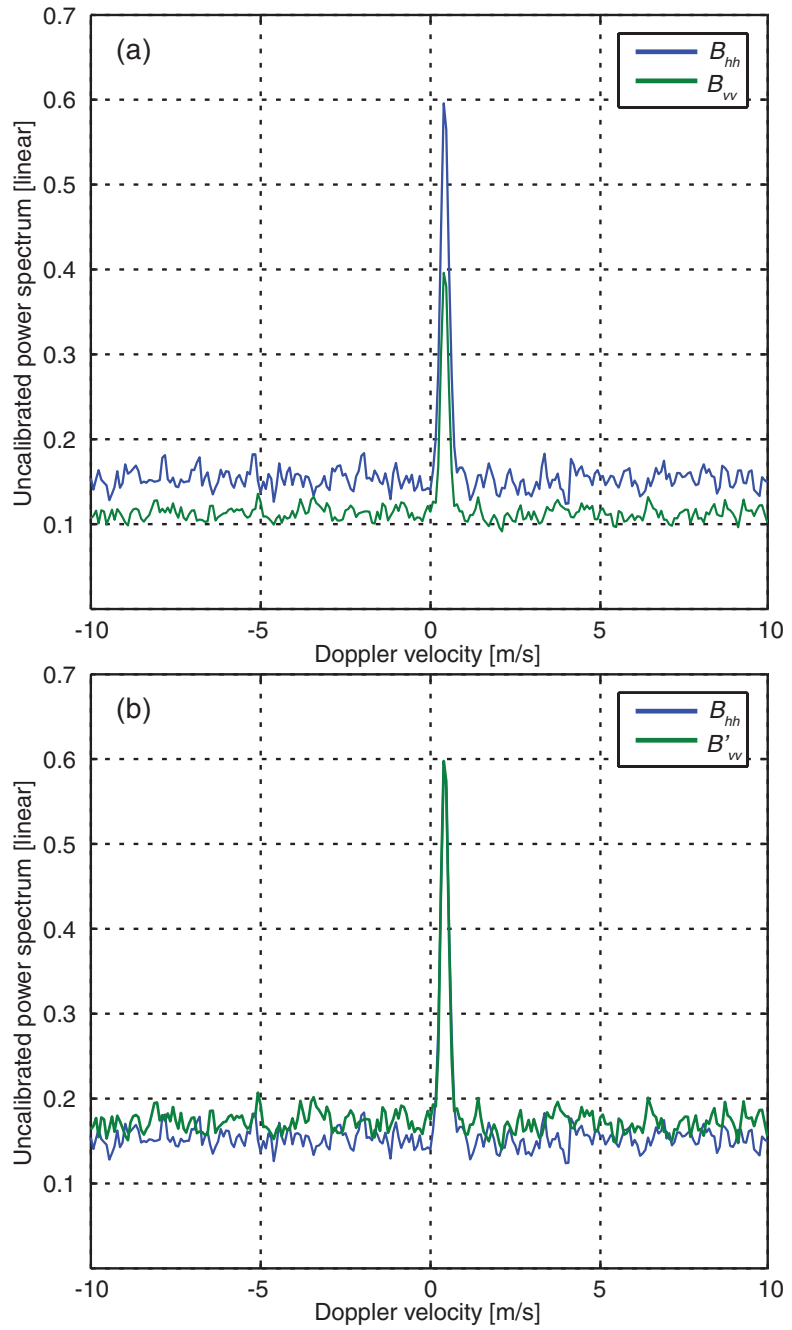

Figure 4. (a) Uncalibrated power spectra in the horizontal (blue line) and vertical (green line) channels. Displayed observations were obtained with the vertically pointed radar in light rain. (b) Uncalibrated power spectrum in the horizontal channel (blue line) and corrected power spectrum in the vertical channel (green line). The same data as in (a) are used. Mean noise levels of $B_{\mathrm{hh}}$ and $B_{\mathrm{vV}}^{\prime}$, estimated using the Hildebrand-Sekhon algorithm, are 0.153 and 0.169 , respectively. Note that this case was chosen to illustrate the correction. Due to low signal-to-noise ratios, such spectra were not used for the calculation of the coefficient $K_{\mathrm{a}}$ (see Sect. 2.6).

$B_{\mathrm{vv}}\left(\omega_{k}\right)$, and $B_{\mathrm{vv}}^{\prime}\left(\omega_{k}\right)$ are shown in Fig. 4. We denote the coherency matrix with the corrected elements as $\mathbf{B}^{\prime}\left(\omega_{k}\right)$.

As mentioned in Sect. 2.1, the calibration of the receiver slowly fluctuates during operation. This causes variations of \pm 0.06 in $K_{\mathrm{a}}$. The range of $K_{\mathrm{a}}$ can be constrained by performing recalibrations during light rain.
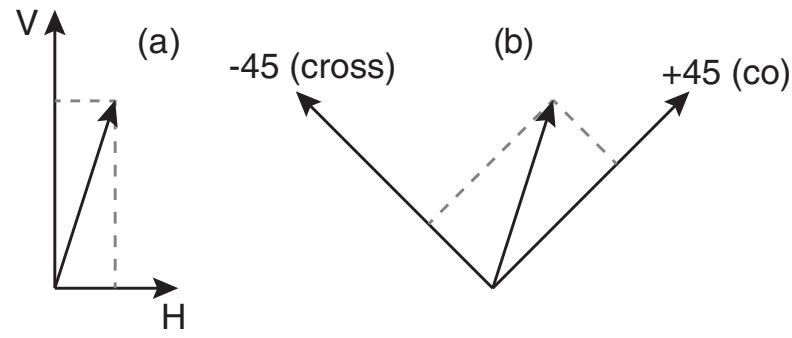

Figure 5. The Jones vector of a received signal represented in the description (a) and slanted (b) polarization basis.

\subsection{Representation of the coherency matrix in the slanted basis}

It is known that the antenna coupling produces biases in polarimetic variables. Such biases hamper shape and orientation retrievals. The antenna coupling can be directly determined in LDR-mode cloud radars from vertical measurements in light rain or drizzle when particles can be assumed to be spherical. In this case the cross-polarized returned signal is caused only by the coupling (Chandrasekar and Keeler, 1993). In cloud radars with the hybrid mode the estimation of antenna influence is not straightforward as the major part of the returned signal in both channels is produced by scatterers. In this section we show the representation of the coherency matrix $\mathbf{B}^{\prime}\left(\omega_{k}\right)$ in the polarization basis rotated by $45^{\circ}$ with respect to the description one. The Jones vector of a received signal in description and slanted basis is shown in Fig. 5. Such representation provides the co-polarized and crosspolarized components that would be measured by a cloud radar with slanted polarimetric basis. These components can be used for the correction algorithm proposed by Myagkov et al. (2015). In addition, the change of the polarization basis makes it possible to calculate the depolarization ratio and the co-cross-channel correlation coefficient that cannot be directly measured in the hybrid mode.

The corrected coherency matrix $\mathbf{B}^{\prime}\left(\omega_{k}\right)$ can be represented in the linear basis rotated by $45^{\circ}$ with respect to the description basis:

$\mathbf{B}_{\mathrm{S}}\left(\omega_{k}\right)=\mathbf{F}^{T} \mathbf{B}^{\prime}\left(\omega_{k}\right) \mathbf{F}$,

where $T$ is the transpose sign and $\mathbf{F}$ is the rotational operator:

$\mathbf{F}=\frac{1}{\sqrt{2}}\left(\begin{array}{cc}1 & 1 \\ -1 & 1\end{array}\right)$

The elements of $\mathbf{B}_{\mathrm{S}}\left(\omega_{k}\right)$ can be calculated as follows:

$$
\begin{aligned}
& B_{\mathrm{xx}}\left(\omega_{k}\right)=\frac{1}{2}\left\{B_{\mathrm{hh}}\left(\omega_{k}\right)+B_{\mathrm{vv}}^{\prime}\left(\omega_{k}\right)-2 \operatorname{Re}\left[\dot{B}_{\mathrm{hv}}^{\prime}\left(\omega_{k}\right)\right]\right\}, \\
& \dot{B}_{\mathrm{xc}}\left(\omega_{k}\right)=\frac{1}{2}\left\{B_{\mathrm{hh}}\left(\omega_{k}\right)-B_{\mathrm{vv}}^{\prime}\left(\omega_{k}\right)+2 i \operatorname{Im}\left[\dot{B}_{\mathrm{hv}}^{\prime}\left(\omega_{k}\right)\right]\right\}, \\
& B_{\mathrm{cc}}\left(\omega_{k}\right)=\frac{1}{2}\left\{B_{\mathrm{hh}}\left(\omega_{k}\right)+B_{\mathrm{vv}}^{\prime}\left(\omega_{k}\right)+2 \operatorname{Re}\left[\dot{B}_{\mathrm{hv}}^{\prime}\left(\omega_{k}\right)\right]\right\} .
\end{aligned}
$$


In the slanted basis we use the indexes $\mathrm{c}$ and $\mathrm{x}$ to denote the co-polarized and cross-polarized components, respectively. Note that these components would be directly measured by a cloud radar with the slanted polarimetric basis.

The coherency matrix $\mathbf{B}_{\mathrm{S}}\left(\omega_{k}\right)$ can be considered as the coherency matrix measured in the slanted-linear-depolarization ratio mode (SLDR mode) that was used for the shape classification by Matrosov et al. (2012). In the SLDR mode and hybrid mode with transmission phase difference $\Delta \varphi_{\mathrm{T}}=0^{\circ}$ the transmitted signals have the same polarization state. The difference between these polarimetric configurations is the $45^{\circ}$ rotation of the receiving basis that we perform in Eq. (11). Note that Eq. (11) allows for representation of the coherency matrix measured in the SLDR mode on a horizontal-vertical basis and, thus, can be used to retrieve polarimetric variables such as $Z_{\mathrm{DR}}$ and $\rho_{\mathrm{HV}}$.

For the subsequent data analysis we define spectral components $\omega_{p}$ where the backscattered signal is detected in the elements $B_{\mathrm{cc}}\left(\omega_{k}\right)$ and $B_{\mathrm{xx}}\left(\omega_{k}\right)$. The threshold applied for the detection is calculated as follows:

$B_{\mathrm{Tc}, \mathrm{Tx}}=N_{\mathrm{c}, \mathrm{x}}\left(1+\frac{Q}{\sqrt{N_{\mathrm{s}}}}\right)$.

In Eq. (16) $N_{\mathrm{c}, \mathrm{x}}$ is the mean power of noise of $B_{\mathrm{cc}}\left(\omega_{k}\right)$ and $B_{\mathrm{xx}}\left(\omega_{k}\right)$, respectively. We use the value of $Q=5$ which is applied for the thresholding in the operational MIRA-35 radars (Görsdorf et al., 2015).

Further we remove the mean noise levels from the elements $B_{\mathrm{cc}}\left(\omega_{p}\right)$ and $B_{\mathrm{xx}}\left(\omega_{p}\right)$ :

$B_{\mathrm{cc}}^{\prime}\left(\omega_{p}\right)=B_{\mathrm{cc}}\left(\omega_{p}\right)-N_{c}$

$B_{\mathrm{XX}}^{\prime}\left(\omega_{p}\right)=B_{\mathrm{xx}}\left(\omega_{p}\right)-N_{x}$.

The correlation between noise in the orthogonal components is negligible and, thus, does not influence the element $\dot{B}_{\text {xc }}\left(\omega_{p}\right)$ significantly. We represent the resulting coherency matrix as follows:

$\mathbf{B}_{\mathrm{S}}^{\prime}\left(\omega_{p}\right)=\left(\begin{array}{ll}B_{\mathrm{xx}}^{\prime}\left(\omega_{p}\right) & \dot{B}_{\mathrm{xc}}\left(\omega_{p}\right) \\ \dot{B}_{\mathrm{xc}}^{*}\left(\omega_{p}\right) & B_{\mathrm{cc}}^{\prime}\left(\omega_{p}\right)\end{array}\right)$.

\subsection{Correction of the coherency matrix for the antenna coupling}

We decompose the coherency matrix $\mathbf{B}_{\mathrm{S}}^{\prime}\left(\omega_{p}\right)$ into nonpolarized and fully polarized parts (Born and Wolf, 1975):

$\mathbf{B}_{\mathrm{S}}^{\prime}\left(\omega_{p}\right)=A_{\mathrm{S}}\left(\omega_{p}\right) \mathbf{I}+\left(\begin{array}{cc}B_{\mathrm{S}}\left(\omega_{p}\right) & \dot{D}_{\mathrm{S}}\left(\omega_{p}\right) \\ \dot{D}_{\mathrm{S}}^{*}\left(\omega_{p}\right) & C_{\mathrm{S}}\left(\omega_{p}\right)\end{array}\right)$,

with the condition:

$B_{\mathrm{S}}\left(\omega_{p}\right) C_{\mathrm{S}}\left(\omega_{p}\right)-\left|\dot{D}_{\mathrm{S}}\left(\omega_{p}\right)\right|^{2}=0$

where $\mathbf{I}$ is a $2 \times 2$ unit matrix. $A_{\mathrm{S}}\left(\omega_{p}\right), B_{\mathrm{S}}\left(\omega_{p}\right), C_{\mathrm{S}}\left(\omega_{p}\right)$, and $\dot{D}_{\mathrm{S}}\left(\omega_{p}\right)$ can be calculated with the following equations (Kanareykin et al., 1966; Born and Wolf, 1975):

$$
\begin{aligned}
& A_{\mathrm{S}}\left(\omega_{p}\right)= \\
& \frac{1}{2}\left(\operatorname{Sp}\left[\mathbf{B}_{\mathrm{S}}^{\prime}\left(\omega_{p}\right)\right]-\left\{\operatorname{Sp}^{2}\left[\mathbf{B}_{\mathrm{S}}^{\prime}\left(\omega_{p}\right)\right]-4 \operatorname{det}\left[\mathbf{B}_{\mathrm{S}}^{\prime}\left(\omega_{p}\right)\right]\right\}^{1 / 2}\right), \\
& B_{\mathrm{S}}\left(\omega_{p}\right)= \\
& \frac{1}{2}\left(B_{\mathrm{xx}}^{\prime}\left(\omega_{p}\right)-B_{\mathrm{cc}}^{\prime}\left(\omega_{p}\right)+\left\{\operatorname{Sp}^{2}\left[\mathbf{B}_{\mathrm{S}}^{\prime}\left(\omega_{p}\right)\right]-4 \operatorname{det}\left[\mathbf{B}_{\mathrm{S}}^{\prime}\left(\omega_{p}\right)\right]\right\}^{1 / 2}\right), \\
& C_{\mathrm{S}}\left(\omega_{p}\right)= \\
& \frac{1}{2}\left(B_{\mathrm{cc}}^{\prime}\left(\omega_{p}\right)-B_{\mathrm{xx}}^{\prime}\left(\omega_{p}\right)+\left\{\operatorname{Sp}^{2}\left[\mathbf{B}_{\mathrm{S}}^{\prime}\left(\omega_{p}\right)\right]-4 \operatorname{det}\left[\mathbf{B}_{\mathrm{S}}^{\prime}\left(\omega_{p}\right)\right]\right\}^{1 / 2}\right),
\end{aligned}
$$

$\dot{D}_{\mathrm{S}}\left(\omega_{p}\right)=\dot{B}_{\mathrm{xc}}\left(\omega_{p}\right)$.

Here $\mathrm{Sp}$ is the matrix trace and det is the matrix determinant.

Applying the method described by Myagkov et al. (2015), we remove the influence of antenna coupling on the elements $A_{\mathrm{S}}\left(\omega_{p}\right), B_{\mathrm{S}}\left(\omega_{p}\right)$, and $C_{\mathrm{S}}\left(\omega_{p}\right)$. Note that in this study the fully polarized part of the co-polarized component is described by $C_{S}\left(\omega_{p}\right)$. The calculated variables are denoted as $A_{\mathrm{S}}^{\prime}\left(\omega_{p}\right), B_{\mathrm{S}}^{\prime}\left(\omega_{p}\right)$, and $C_{\mathrm{S}}^{\prime}\left(\omega_{p}\right)$, respectively. The corrected value $\dot{D}_{S}^{\prime}\left(\omega_{p}\right)$ can be found using $B_{S}^{\prime}\left(\omega_{p}\right), C_{S}^{\prime}\left(\omega_{p}\right)$ in Eq. (21). Reverse rotation of the slanted basis allows for the calculation of the elements $A\left(\omega_{p}\right), B\left(\omega_{p}\right)$, and $C\left(\omega_{p}\right)$ in the description basis:

$$
\begin{aligned}
& A\left(\omega_{p}\right)=A_{\mathrm{S}}^{\prime}\left(\omega_{p}\right), \\
& B\left(\omega_{p}\right)=0.5\left(B_{\mathrm{S}}^{\prime}\left(\omega_{p}\right)+C_{\mathrm{S}}^{\prime}\left(\omega_{p}\right)\right. \\
& \left.+2 \operatorname{Re}\left\{\sqrt{B_{\mathrm{S}}^{\prime}\left(\omega_{p}\right) C_{\mathrm{S}}^{\prime}\left(\omega_{p}\right)} e^{i \arg \left[\dot{D}_{\mathrm{S}}\left(\omega_{p}\right)\right]}\right\}\right), \\
& C\left(\omega_{p}\right)=0.5\left(B_{\mathrm{S}}^{\prime}\left(\omega_{p}\right)+C_{\mathrm{S}}^{\prime}\left(\omega_{p}\right)\right. \\
& \left.-2 \operatorname{Re}\left\{\sqrt{B_{\mathrm{S}}^{\prime}\left(\omega_{p}\right) C_{\mathrm{S}}^{\prime}\left(\omega_{p}\right)} e^{i \arg \left[\dot{D}_{\mathrm{S}}\left(\omega_{p}\right)\right]}\right\}\right) .
\end{aligned}
$$

\subsection{Spectral polarimetric variables}

From $A\left(\omega_{p}\right), B\left(\omega_{p}\right)$, and $C\left(\omega_{p}\right)$, spectral polarimetric variables can be obtained. In the following, we omit the word "spectral" for brevity. Differential reflectivity $Z_{\mathrm{DR}}\left(\omega_{p}\right)$, correlation coefficient $\rho_{\mathrm{HV}}\left(\omega_{p}\right)$, differential phase shift $\varphi_{\mathrm{DP}}\left(\omega_{p}\right), \operatorname{SLDR}\left(\omega_{p}\right)$, and co-cross-channel correlation coefficient $\rho_{\mathrm{CX}}\left(\omega_{p}\right)$ are defined as follows:

$$
\begin{aligned}
& Z_{\mathrm{DR}}\left(\omega_{p}\right)=\frac{A\left(\omega_{p}\right)+B\left(\omega_{p}\right)}{A\left(\omega_{p}\right)+C\left(\omega_{p}\right)}, \\
& \rho_{\mathrm{HV}}\left(\omega_{p}\right)= \\
& \left\{\frac{B\left(\omega_{p}\right) C\left(\omega_{p}\right)}{\left[A\left(\omega_{p}\right)+B\left(\omega_{p}\right)\right]\left[A\left(\omega_{p}\right)+C\left(\omega_{p}\right)\right]}\right\}^{1 / 2}, \\
& \varphi_{\mathrm{DP}}\left(\omega_{p}\right)=\arg \left[\dot{B}_{\mathrm{hv}}^{\prime}\left(\omega_{p}\right)\right],
\end{aligned}
$$


$\operatorname{SLDR}\left(\omega_{p}\right)=\frac{A_{\mathrm{S}}^{\prime}\left(\omega_{p}\right)+B_{\mathrm{S}}^{\prime}\left(\omega_{p}\right)}{A_{\mathrm{S}}^{\prime}\left(\omega_{p}\right)+C_{\mathrm{S}}^{\prime}\left(\omega_{p}\right)}$

$\rho_{\mathrm{CX}}\left(\omega_{p}\right)=$

$\left\{\frac{B_{\mathrm{S}}^{\prime}\left(\omega_{p}\right) C_{\mathrm{S}}^{\prime}\left(\omega_{p}\right)}{\left[A_{\mathrm{S}}^{\prime}\left(\omega_{p}\right)+B_{\mathrm{S}}^{\prime}\left(\omega_{p}\right)\right]\left[A_{\mathrm{S}}^{\prime}\left(\omega_{p}\right)+C_{\mathrm{S}}^{\prime}\left(\omega_{p}\right)\right]}\right\}^{1 / 2}$.

In order to check the quality of the polarimetric measurements of MIRA-35 in the hybrid mode, we performed vertical-stare measurements of a cloud system that passed over the METEK site on 1 May 2014. Figure 8 shows SNR (a) and the polarimetric variables (b-f) derived with Eqs. (29)-(33), respectively. Presented parameters were obtained for the spectral line for which the maximum signal was observed. From 17:45 to 18:00 UTC a melting layer is visible at $1.7 \mathrm{~km}$ height, indicated by enhanced values of SNR and SLDR. Below the melting layer light rain occurred whereas ice crystals were present above. The comparison of Fig. 8b-f with (a) shows that the polarimetric parameters could not be obtained for all data points because the quality criterion of Eq. (16) is not fulfilled when the SNR is too low. At a lower SNR, the influence of noise becomes significant resulting in high biases and variability in all polarimetric variables.

It can be seen in Fig. $8 \mathrm{~b}$ and $\mathrm{d}$ that on average values of $Z_{\mathrm{DR}}$ and $\varphi_{\mathrm{DP}}$ in clouds and precipitation are close to $0 \mathrm{~dB}$ and $0^{\circ}$, respectively, which is the case when particles can be considered as spheres or randomly oriented in the polarization plane. Areas with slightly increased values of $Z_{\mathrm{DR}}$ and $\varphi_{\mathrm{DP}}$ are caused by noise as these areas are in correlation with decreasing SNR, especially along cloud edges. Insects are characterized by values of $Z_{\mathrm{DR}}$ and $\varphi_{\mathrm{DP}}$ that lie outside of the color bars.

In rain, the correlation coefficient $\rho_{\mathrm{HV}}$ is 1 , which is consistent with high values of this parameter observed by polarimetric weather radars (Mudukutore et al., 1995; Wang et al., 2006). Slightly lower values of about 0.995 were observed in areas with ice particles producing slight depolarization. In the highly depolarizing melting layer, $\rho_{\mathrm{HV}}$ is below 0.95 .

Values of SLDR measured vertically in rain, in the melting layer, in ice areas, and in regions dominated by scattering from insects are consistent with direct measurements of LDR (Lohmeier et al., 1997; Di Girolamo et al., 2012; Görsdorf et al., 2015). Values of $\rho_{\mathrm{CX}}$ for meteorological scatterers are 0 as it follows from theoretical considerations (Myagkov et al., 2015). Insects can be considered as point depolarizing targets and therefore produce high $\rho_{\mathrm{CX}}$ (Myagkov et al., 2015).

Polarimetric variables obtained for the time period from 17:55 to 18:00 UTC and the height range from 500 to $1700 \mathrm{~m}$, where light rain was observed, are close to those that would be measured in rain by a hypothetical ideal radar, i.e., $Z_{\mathrm{DR}}=1(0 \mathrm{~dB}), \varphi_{\mathrm{DP}}=0^{\circ}, \rho_{\mathrm{HV}}=1, \mathrm{SLDR}=0(-\infty \mathrm{dB})$, and $\rho_{\mathrm{CX}}=0$ (in the limit approximation given in Myagkov et al., 2015). For the comparison and the estimation of the antenna quality, we show values of polarimetric pa-
Table 2. Polarimetric variables calculated without the correction for the antenna coupling. Values are based on measurements with the vertically pointed cloud radar in light rain on the 1 May 2014. The statistics are based on the height range from 500 to $1700 \mathrm{~m}$ and the time period from 17:55 to 18:00 UTC.

\begin{tabular}{lrr}
\hline Variable & Mean value & Standard deviation \\
\hline$Z_{\mathrm{DR}}$ & $1.011(0.048 \mathrm{~dB})$ & 0.017 \\
$\rho_{\mathrm{HV}}$ & 0.9976 & $4.8 \times 10^{-4}$ \\
$\varphi_{\mathrm{DP}}$ & $-0.16^{\circ}$ & $0.35^{\circ}$ \\
$\mathrm{SLDR}$ & $1.2 \times 10^{-3}(-29.3 \mathrm{~dB})$ & $2.2 \times 10^{-4}$ \\
$\rho_{\mathrm{CX}}$ & 0.089 & 0.046 \\
\hline
\end{tabular}

rameters without the correction for antenna coupling in Table 2 . We calculated these variables by inserting the elements $A_{\mathrm{S}}\left(\omega_{p}\right), B_{\mathrm{S}}\left(\omega_{p}\right)$, and $C_{\mathrm{S}}\left(\omega_{p}\right)$ instead of $A_{\mathrm{S}}^{\prime}\left(\omega_{p}\right), B_{\mathrm{S}}^{\prime}\left(\omega_{p}\right)$, and $C_{\mathrm{S}}^{\prime}\left(\omega_{p}\right)$ in Eqs. (26)-(33).

\subsection{Sensitivity issue}

Splitting the transmitting power into two channels in the hybrid mode worsens the radar sensitivity by $3 \mathrm{~dB}$. In the case when only power spectra $B_{\mathrm{hh}}\left(\omega_{k}\right)$ and $B_{\mathrm{vv}}\left(\omega_{k}\right)$ are available, noncoherent averaging can recover up to $1.5 \mathrm{~dB}$ (Skolnik, 1980). The availability of the full coherency matrix permits the application of coherent averaging based on Eq. (15) which can potentially improve the radar sensitivity by up to $3 \mathrm{~dB}$. Thus, the sensitivity loss due to splitting can be balanced out by the sensitivity gain due to coherent averaging. Applicability of the coherent averaging to weather radars was previously shown by Melnikov et al. (2011).

Coherent averaging can be applied when the received signals in the horizontal and vertical channels are in-phase. In the case of elliptical or circular polarization of the transmitted signal, an additional phase shift can be introduced during processing to fulfill this requirement. As shown in Sect. 2.1, in our case the transmission phase difference is $\Delta \varphi_{\mathrm{T}}=-0.9^{\circ}$, which is considered to be sufficiently low to neglect effects of the phase difference on SNR.

In Fig. $4 \mathrm{~b}$ it can be seen that the mean noise levels in the receiving channels are different. This can hamper the procedure of increasing the sensitivity. Therefore, we adjust the mean noise levels using the coefficient $K_{\mathrm{n}}$ :

$K_{\mathrm{n}}=\frac{N_{\mathrm{h}}}{N_{\mathrm{v}}}$.

For the rain case on 1 May 2014 we found $K_{\mathrm{n}}$ to be $1.32 \pm$ 0.14 . Long-term fluctuations of $K_{\mathrm{n}}$ are of the same order of magnitude as for $K_{\mathrm{a}}$. Using $K_{\mathrm{n}}$ instead of the coefficient $K_{\mathrm{a}}$ in Eqs. (9) and (10), we corrected the elements $B_{\mathrm{vv}}\left(\omega_{k}\right)$ and $\dot{B}_{\mathrm{hv}}\left(\omega_{k}\right)$ for different noise levels, which were then inserted into Eq. (15) to perform the coherent averaging.

Another factor that can affect the utilization of Eq. (15) is the differential phase shift introduced by the propagation 


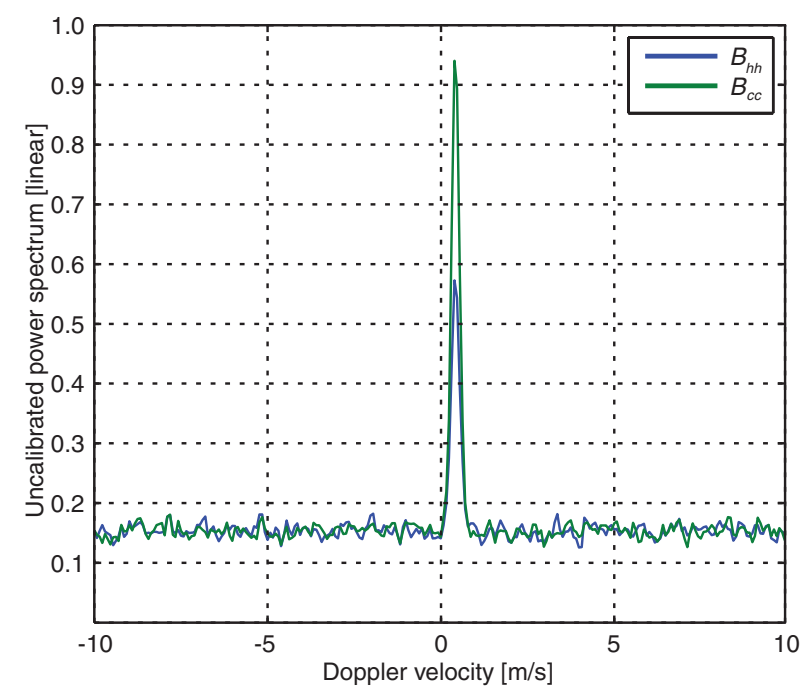

Figure 6. Power spectrum in the horizontal channel (blue line) and power spectrum after coherent averaging (green line). The same data as in Fig. 4 are used.

and backscattering properties of the scatterers. As mentioned in Sect. 2.1, the orientation of particles can be assumed to be distributed uniformly in the polarization plane when the radar is pointed vertically. In this case both backscattering and propagation differential phase shift are 0 . Nevertheless, differential phase effects should be accounted for in the case of utilization of the $35 \mathrm{GHz}$ cloud radar at low elevations for precipitation observations. For instance, Matrosov et al. (1999) showed that at $35 \mathrm{GHz}$, the propagation and backscattering differential phase shift in rain stronger than $5 \mathrm{~mm} \mathrm{~h}^{-1}$ can exceed $1^{\circ} \mathrm{km}^{-1}$ and $5^{\circ}$, respectively. Note that in this paper we do not consider corrections for the differential phase shift introduced by scatterers.

The results of Eq. (15) are shown in Fig. 6 for an arbitrary example case. It can be seen that maximums in $B_{\mathrm{cc}}\left(\omega_{k}\right)$ and $B_{\mathrm{hh}}\left(\omega_{k}\right)$ are 0.93 and 0.56 , respectively, while the standard deviations of noise are 0.01 and 0.011 (arbitrary units), respectively. The noise levels of $B_{\mathrm{cc}}\left(\omega_{k}\right)$ and $B_{\mathrm{hh}}\left(\omega_{k}\right)$ are 0.16 . Note that all the values are given in arbitrary units. Thus, the SNR calculated from $B_{\mathrm{cc}}\left(\omega_{k}\right)$ is nearly 2 times higher than the one calculated using $B_{\mathrm{hh}}\left(\omega_{k}\right)$. The power spectra $B_{\mathrm{cc}}\left(\omega_{k}\right)$ can be used for the standard processing, i.e., for the detection and the estimation of spectral moments. In this case the total power transmitted by the radar instead of the power transmitted in the horizontal channel should be used for the calculation of reflectivity.

In Fig. 7 the height-time cross sections of SNR calculated from $B_{\mathrm{hh}}\left(\omega_{k}\right)$ and $B_{\mathrm{cc}}\left(\omega_{k}\right)$ are shown. For the thresholding and the SNR calculation we use the standard processing implemented in MIRA-35 cloud radar (Görsdorf et al., 2015). It can be seen that the coherent averaging results in more data points, which is especially of benefit for the detection efficiency of high-level clouds. (a) Signal-to-noise ratio in the horizontal channel [dB]

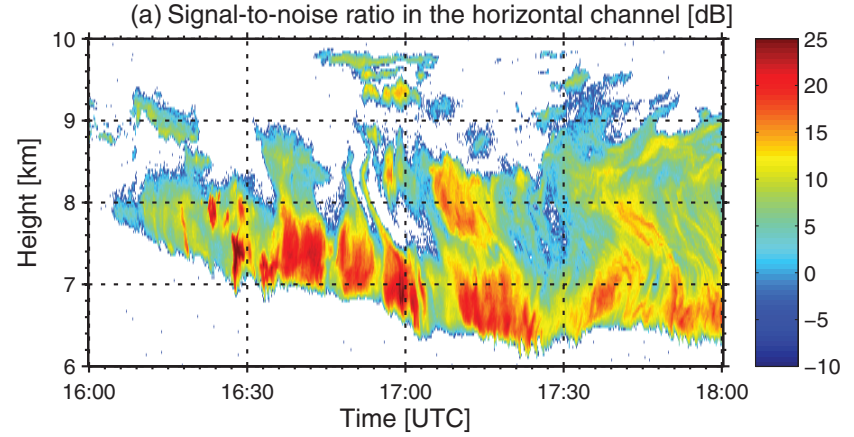

(b) Signal-to-noise ratio of the coherently averaged signal [dB]

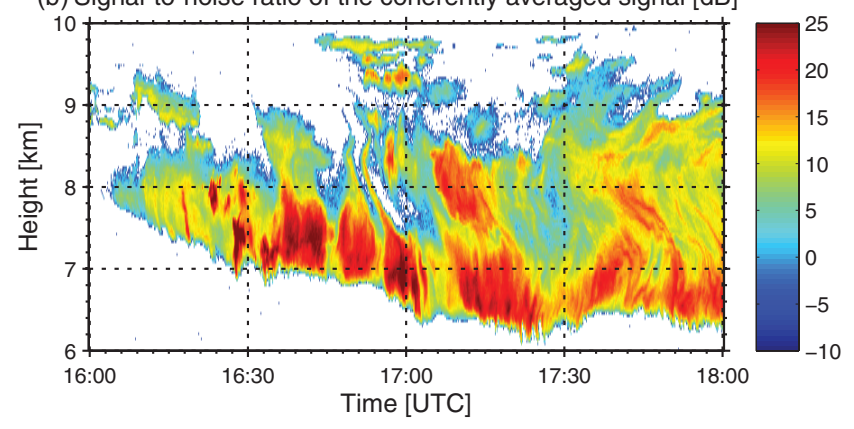

Figure 7. Time-height cross sections of signal-to-noise ratios calculated from $B_{\mathrm{hh}}$ (a) and $B_{\mathrm{cc}}$ (b) measured at Elmshorn, Germany, on 1 May 2014. The number of data points (especially in high-level clouds) in panel (b) is higher in comparison with (a) because of higher sensitivity.

\section{Shape and orientation retrieval}

As shown in Sect. 2.6 the cloud radar with the hybrid mode permits us to obtain the set of spectral polarimetric variables (Eqs. 29-33) that are not available in the LDR mode. In this section we show how this additional information can be used to quantitatively estimate shape and orientation of cloud particles. The approach presented in the following is based on a combination of established spheroidal models (Matrosov, 1991a; Ryzhkov, 2001; Bringi and Chandrasekar, 2001) that were developed to describe the polarimetric variables.

\subsection{Backscattering model}

It is known that particles with sizes much smaller than the wavelength of a radar can be approximated by a spheroid. Matrosov (2015) shows that this approximation is valid in the case of ice-particle observations with cloud radars. Scattering properties of a spheroid are often described using the Jones representation in the linear polarization basis by a $2 \times 2$ backscattering matrix:

$$
\mathbf{S}=\left(\begin{array}{ll}
\dot{S}_{\mathrm{hh}} & \dot{S}_{\mathrm{hv}} \\
\dot{S}_{\mathrm{vh}} & \dot{S}_{\mathrm{vv}}
\end{array}\right)
$$


(a) Signal-to-noise ratio in the horizontal channel [dB]

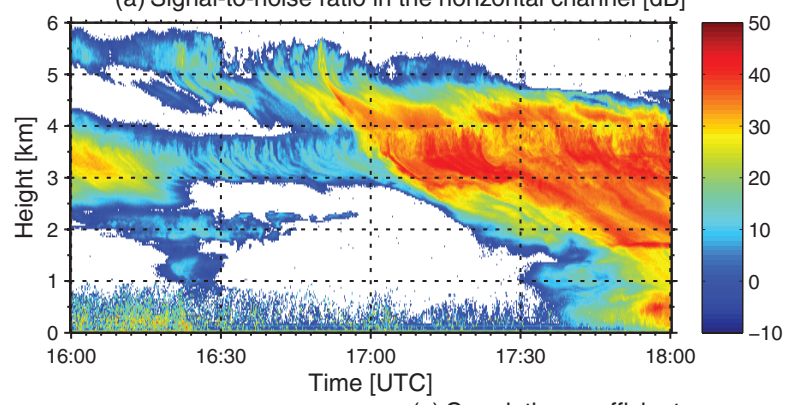

(c) Correlation coefficient

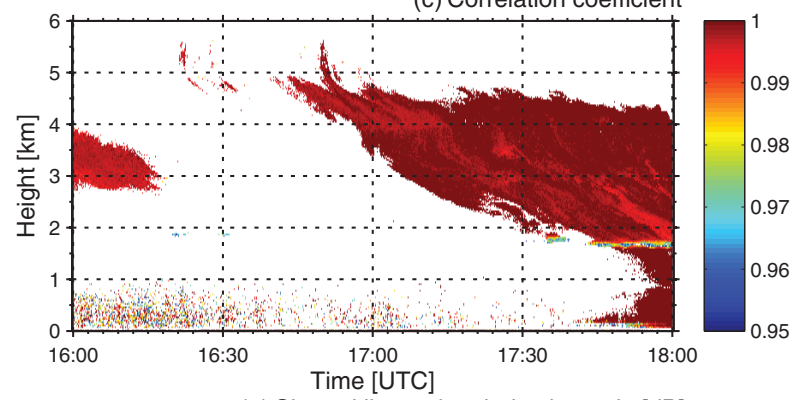

(e) Slanted linear depolarization ratio [dB]

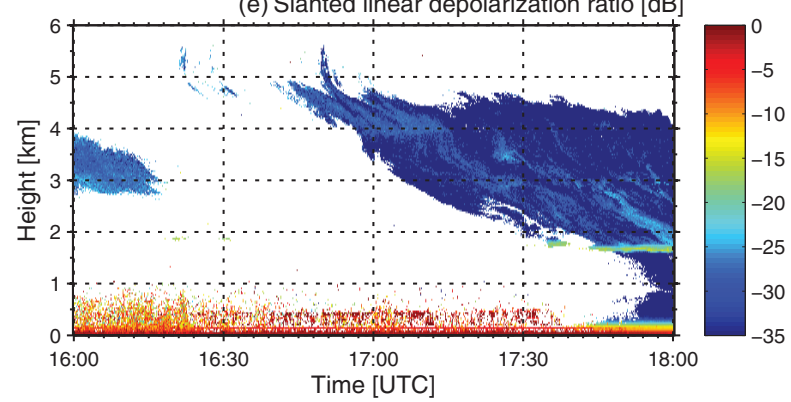

(b) Differential reflectivity $[\mathrm{dB}]$

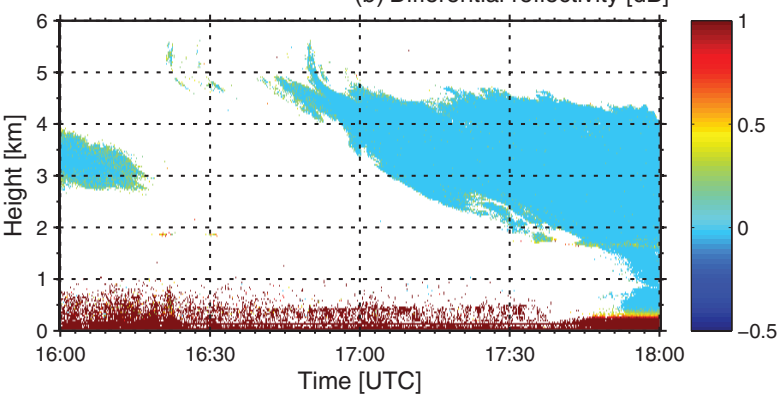

(d) Differential phase shift [deg]
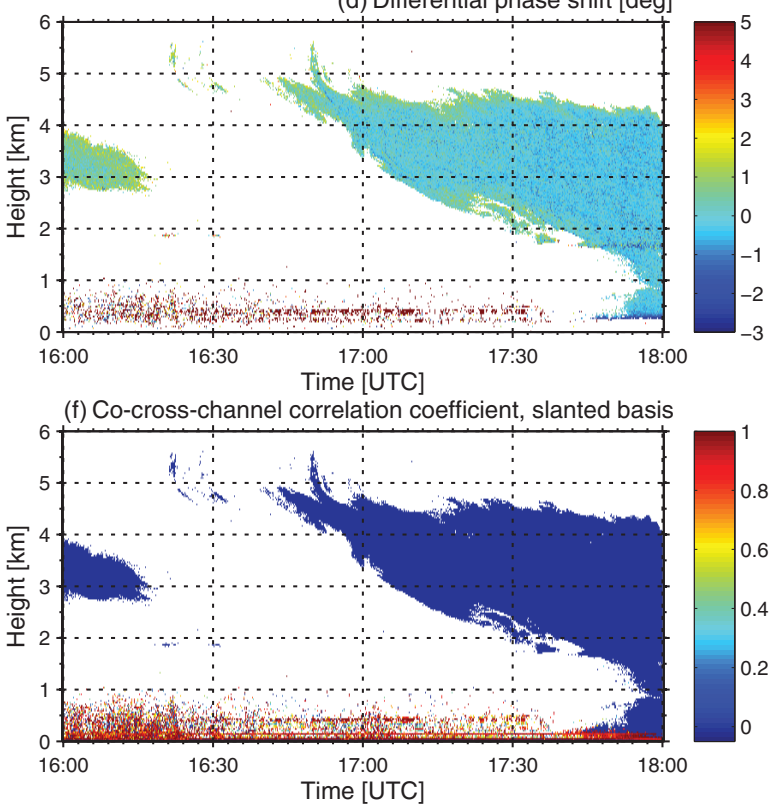

Figure 8. Time-height cross sections of the signal-to-noise ratio in the horizontal channel (a), differential reflectivity $Z_{\mathrm{DR}}(\mathbf{b})$, correlation coefficient $\rho_{\mathrm{HV}}(\mathbf{c})$, differential phase shift $\varphi_{\mathrm{DP}}(\mathbf{d})$, slanted linear depolarization ratio SLDR (e), and co-cross-channel correlation coefficient in the slanted basis $\rho_{\mathrm{CX}}$ for the measurements taken at Elmshorn, Germany, on 1 May 2014.

The elements of the backscattering matrix $\mathbf{S}$ are calculated as follows (Bringi and Chandrasekar, 2001, ch. 2):

$$
\begin{aligned}
& \dot{S}_{\mathrm{hh}}=\frac{k_{0}^{2}}{4 \pi \epsilon_{0}}\left[\alpha_{1}+\left(\alpha_{2}-\alpha_{1}\right) \sin ^{2} \theta \sin ^{2} \varphi\right], \\
& \dot{S}_{\mathrm{hv}}=\dot{S}_{\mathrm{vh}}= \\
& \frac{k_{0}^{2}}{4 \pi \epsilon_{0}}\left[\frac{\left(\alpha_{2}-\alpha_{1}\right)}{2}\left(\cos \psi \sin ^{2} \theta \sin 2 \varphi+\sin \psi \sin 2 \theta \sin \varphi\right)\right], \\
& \dot{S}_{\mathrm{vv}}=\frac{k_{0}^{2}}{4 \pi \epsilon_{0}}\left[\alpha_{1}+\left(\alpha_{2}-\alpha_{1}\right)\right. \\
& \left.\left(\cos ^{2} \psi \sin ^{2} \theta \cos ^{2} \varphi+\sin ^{2} \psi \cos ^{2} \theta+\frac{\sin 2 \psi \sin 2 \theta \cos \varphi}{2}\right)\right],
\end{aligned}
$$

where $k_{0}$ is the wavenumber, $\epsilon_{0}$ is the vacuum permittivity, $\psi$ is the angle between the unit vector $\boldsymbol{e}_{z}$ (Fig. 3) and the zenith direction. The angle $\psi$ is further denoted as the elevation angle. $\theta$ and $\varphi$ are angles defining the orientation of the spheroid, which is illustrated in Fig. 9. $\alpha_{1,2}$ are polarizability elements:

$\alpha_{1,2}=V \epsilon_{0}\left(\epsilon_{\mathrm{r}}-1\right) \Lambda_{1,2}$.

In Eq. (39) $V$ is the volume of the spheroid, $\epsilon_{\mathrm{r}}$ is the relative permittivity, and $\Lambda_{1,2}$ can be found as follows:

$$
\Lambda_{1,2}=\frac{1}{\left(\epsilon_{\mathrm{r}}-1\right) \lambda_{1,2}+1},
$$

where $\lambda_{1,2}$ are depolarizing factors. The depolarizing factors for prolate and oblate spheroids are described as follows:

$\lambda_{2}($ prolate $)=\frac{1-b^{2}}{b^{2}}\left(-1+\frac{1}{2 b} \ln \frac{1+b}{1-b}\right) ;$

$b^{2}=1-\left(\frac{1}{\rho_{g}}\right)^{2}, \rho_{g} \geq 1$,

$\lambda_{2}$ (oblate $)=\frac{1+f^{2}}{f^{2}}\left(1-\frac{1}{f} \tan ^{-1} f\right) ;$ 
$f^{2}=\left(\frac{1}{\rho_{g}}\right)^{2}-1,0<\rho_{g} \leq 1$,

$\lambda_{1}=\frac{1-\lambda_{2}}{2}$.

In Eqs. (41) and (42) $\rho_{g}$ is the axis ratio of the spheroid.

In the following, we consider only ice particles. In the microwave region the real part of $\epsilon_{\mathrm{r}}$ for pure ice is approximately 3.168. The imaginary part is several orders of magnitude lower than the real part (Ray, 1972) and, therefore, we neglect it. In this case the elements of the backscattering matrix $\mathbf{S}$ are real numbers.

Further we define the polarizability ratio:

$\rho_{e}=\frac{\alpha_{2}}{\alpha_{1}}$

$\rho_{e}$ is a function of permittivity and axis ratio $\rho_{g}$ and is independent of particle volume $V$. As was shown in a review of Oguchi (1983), the permittivity and density of ice crystals are related almost linearly. The relationship between $\rho_{e}, \rho_{g}$, and particle density is shown in Fig. 10.

The backscattering matrix of $N$ particles dispersed in a certain volume can be written as follows:

$\mathbf{S}_{\Sigma}=\sum_{j=1}^{N} \mathbf{S}_{j} e^{2 i k_{0} r_{j}}$,

where $\mathbf{S}_{j}$ and $r_{j}$ are the backscattering matrix and the distance from the radar of the $j$ th particle, respectively.

Assuming complex amplitudes of the horizontal and vertical components of the transmitted signal $\left(\dot{E}_{\mathrm{h}}\right)_{\mathrm{t}}=\left(\dot{E}_{\mathrm{v}}\right)_{\mathrm{t}}=1$, the polarization state corresponds to the one of a wave emitted by an ideal hybrid-mode radar with a transmission phase difference $\Delta \varphi_{\mathrm{T}}=0^{\circ}$.

The complex amplitudes of the horizontal $\left(\dot{E}_{\mathrm{h}}\right)_{\mathrm{r}}$ and vertical $\left(\dot{E}_{\mathrm{V}}\right)_{\mathrm{r}}$ components of the received signal can be derived as follows:

$\left(\dot{E}_{\mathrm{h}}\right)_{\mathrm{r}}=\left(\dot{S}_{\mathrm{hh}}\right)_{\Sigma}\left(\dot{E}_{\mathrm{h}}\right)_{\mathrm{t}}+\left(\dot{S}_{\mathrm{hv}}\right)_{\Sigma}\left(\dot{E}_{\mathrm{v}}\right)_{\mathrm{t}}$,

$\left(\dot{E}_{\mathrm{v}}\right)_{\mathrm{r}}=\left(\dot{S}_{\mathrm{hv}}\right)_{\Sigma}\left(\dot{E}_{\mathrm{h}}\right)_{\mathrm{t}}+\left(\dot{S}_{\mathrm{vv}}\right)_{\Sigma}\left(\dot{E}_{\mathrm{v}}\right)_{\mathrm{t}}$,

where $\left(\dot{S}_{\mathrm{hh}}\right)_{\Sigma},\left(\dot{S}_{\mathrm{hv}}\right)_{\Sigma},\left(\dot{S}_{\mathrm{vh}}\right)_{\Sigma}$, and $\left(\dot{S}_{\mathrm{vv}}\right)_{\Sigma}$ are elements of the backscattering matrix $\mathbf{S}_{\Sigma}$.

Implementation of the subsequent modeling approach is based on the following assumptions.

1. $V, \theta, \varphi, \rho_{g}$ are not correlated with each other.

2. All particles have the same axis ratio $\rho_{g}$.

3. $\varphi$ is uniformly distributed in the range from $-\pi$ to $\pi$.

4. The scattering is noncoherent.

5. Multiple scattering is neglected.

6. Propagation effects are neglected.
We assume that particles falling with the same terminal velocity have comparable size and shape. In this case the first two assumptions are reasonable when polarimetric variables for a certain spectral line are modeled.

Under all above-mentioned assumptions the elements of the coherency matrix can then be found as follows:

$$
\begin{aligned}
& \hat{B}_{\mathrm{hh}}=\left\langle\left(\dot{E}_{\mathrm{h}}\right)_{\mathrm{r}}\left(\dot{E}_{\mathrm{h}}\right)_{\mathrm{r}}^{*}\right\rangle= \\
& F_{1}\left(1+P_{1} T_{1}+F_{2} P_{2} T_{1}+F_{3} P_{2} T_{2}\right), \\
& \hat{B}_{\mathrm{vv}}=\left\langle\left(\dot{E}_{\mathrm{v}}\right)_{\mathrm{r}}\left(\dot{E}_{\mathrm{v}}\right)_{\mathrm{r}}^{*}\right\rangle= \\
& F_{1}\left(1+F_{4} P_{1}+F_{5} P_{1} T_{1}+F_{6} P_{2}+F_{7} P_{2} T_{1}+F_{8} P_{2} T_{2}\right), \\
& \hat{B}_{\mathrm{hv}}=\left\langle\left(\dot{E}_{\mathrm{h}}\right)_{\mathrm{r}}\left(\dot{E}_{\mathrm{v}}\right)_{\mathrm{r}}^{*}\right\rangle= \\
& F_{1}\left(1+F_{9} P_{1} T_{1}+F_{10} P_{1}+F_{10} P_{2} T_{1}+F_{11} P_{2} T_{2}\right) .
\end{aligned}
$$

In Eqs. (48)-(50):

$$
\begin{aligned}
& F_{1}=N\left\langle\alpha_{1}\right\rangle\left(\frac{k_{0}^{2}}{4 \pi \epsilon_{0}}\right)^{2}, \\
& F_{2}=\frac{1}{2} \sin ^{2} \psi \\
& F_{3}=\frac{\left(4-5 \sin ^{2} \psi\right)}{8}, \\
& F_{4}=4 F_{2} \\
& F_{5}=\cos ^{2} \psi-2 \sin ^{2} \psi, \\
& F_{6}=\sin ^{4} \psi \\
& F_{7}=\frac{7}{2} \sin ^{2} \psi-5 \sin ^{4} \psi, \\
& F_{8}=\frac{1}{2}-\frac{35}{8} \sin ^{2} \psi+\frac{35}{8} \sin ^{4} \psi, \\
& F_{9}=\frac{1}{2}+\frac{1}{2} F_{5}, \\
& F_{10}=2 F_{2}, \\
& F_{11}=\frac{1}{4} \cos ^{2} \psi-\sin ^{2} \psi, \\
& P_{1}=\rho_{e}-1, \\
& P_{2}=\left(\rho_{e}-1\right)^{2}, \\
& T_{1}=\left\langle\sin ^{2} \theta\right\rangle, \\
& T_{2}=\left\langle\sin ^{4} \theta\right\rangle .
\end{aligned}
$$

Averaging in Eqs. (51), (64), and (65) is performed over $N$ particles.

We model the probability density function of orientation angle $\theta$ by the function adopted from Kanareykin et al. (1966): 


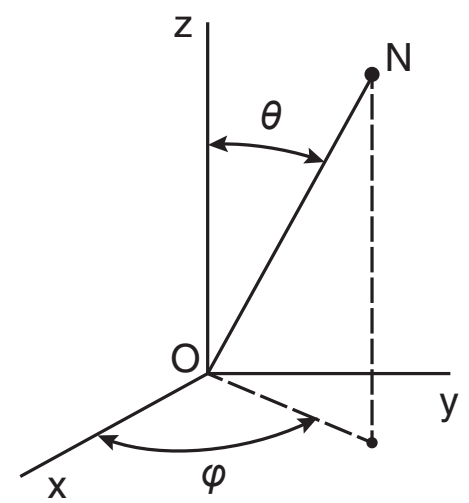

Figure 9. Geometry of spheroid orientation. Adopted from Matrosov (1991a). In the case of $\psi=0^{\circ}, x, y$, and $z$ correspond to $\boldsymbol{e}_{x}$, $\boldsymbol{e}_{y}$, and $\boldsymbol{e}_{z}$, respectively. ON is the symmetry axis of the spheroid.

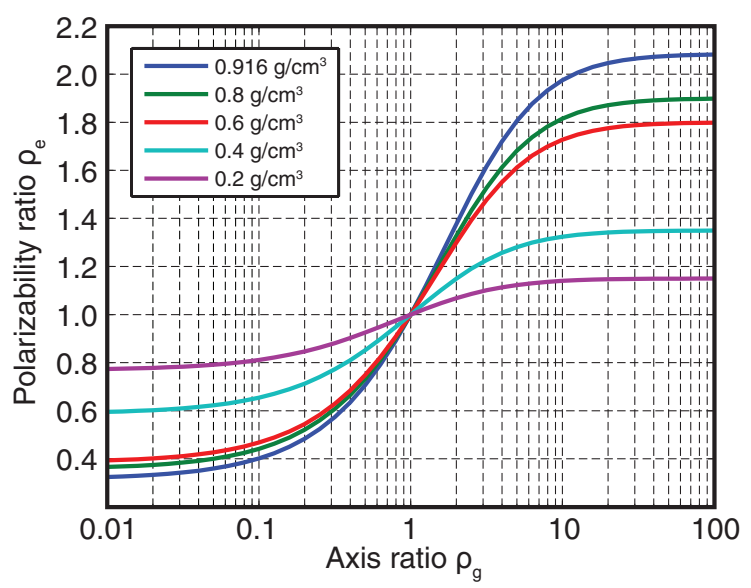

Figure 10. Dependencies of polarizability ratio $\rho_{e}$ on axis ratio of a spheroid $\rho_{g}$ for different densities of ice.

$$
\begin{aligned}
W(\Theta)= & \frac{1-R^{2}}{2 \pi}\left[\frac{1}{1-R^{2} \cos ^{2} 2 \Theta}\right. \\
& \left.+R \cos 2 \Theta \frac{\frac{\pi}{2}+\arcsin (R \cos 2 \Theta)}{\left(1-R^{2} \cos ^{2} 2 \Theta\right)^{3 / 2}}\right], \\
-\frac{\pi}{2} \leq & \leq \frac{\pi}{2},
\end{aligned}
$$

where $R$ is a factor defining the width of the distribution, $\Theta=\theta-\theta_{0}$, with $\theta_{0}$ being the preferable orientation of particles. We consider the preferable orientation to be horizontal, i.e., $\theta_{0}=0$ for oblate spheroids and $\theta_{0}=\pi / 2$ for prolate spheroids, which is consistent with Mitchell (1996). The advantage of using Eq. (66) is that it permits us to model a variety of cases, including a delta distribution $(R=1)$, uniform $(R=0)$, and fully chaotic distributions. In Fig. $11 W(\Theta)$ for different values of $R$ is shown.

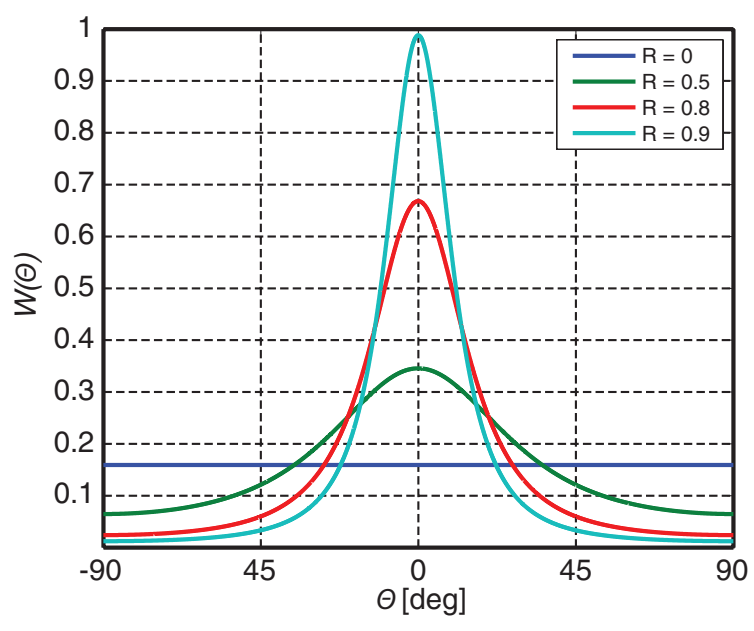

Figure 11. Probability density function of $\Theta$ for different values of $R$. Adopted from Kanareykin et al. (1966).

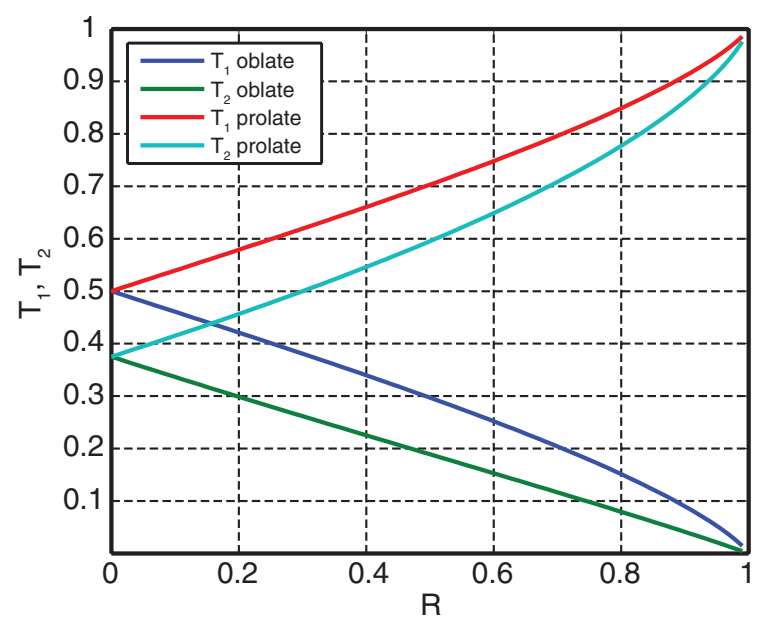

Figure 12. Dependencies of $T_{1}$ and $T_{2}$ on $R$ for oblate and prolate spheroids.

Using Eqs. (64)-(66) the coefficients $T_{1}$ and $T_{2}$ can be calculated as follows:

$$
\begin{aligned}
& T_{1}=\int_{-\pi / 2}^{\pi / 2} \sin ^{2}\left(\Theta+\theta_{0}\right) W(\Theta) d \Theta, \\
& T_{2}=\int_{-\pi / 2}^{\pi / 2} \sin ^{4}\left(\Theta+\theta_{0}\right) W(\Theta) d \Theta .
\end{aligned}
$$

The calculated values of $T_{1}$ and $T_{2}$ are shown in Fig. 12 . For further analysis it is convenient to use the degree of orientation $\rho_{a}$, introduced in Hendry et al. (1976). The degree of orientation $\rho_{a}$ is related to the parameter $T_{1}$ as follows:

$\rho_{a}=1-2 T_{1}$. 
Hendry et al. (1976) considered $\rho_{a}$ only for $\theta_{0}=0$, for which $\rho_{a}$ lies in the range from 0 to 1 . In the case $\theta_{0}=\pi / 2$ values of $\rho_{a}$ are in the range from -1 to 0 . Thus, the absolute value of $\rho_{a}$ represents the degree of orientation, while the sign indicates the preferable orientation of particles (either 0 or $\pi / 2$ ).

The modeled polarimetric variables can be represented using Eqs. (48)-(50):

$$
\begin{aligned}
& \hat{Z}_{\mathrm{DR}}=\frac{\hat{B}_{\mathrm{hh}}}{\hat{B}_{\mathrm{vv}}}, \\
& \hat{\rho}_{\mathrm{HV}}=\frac{\left|\hat{B}_{\mathrm{hv}}\right|}{\sqrt{\hat{B}_{\mathrm{hh}} \hat{B}_{\mathrm{vv}}}}, \\
& \widehat{\mathrm{SLDR}}=\frac{\hat{B}_{\mathrm{hh}}+\hat{B}_{\mathrm{vv}}-2 \operatorname{Re}\left(\hat{B}_{\mathrm{hv}}\right)}{\hat{B}_{\mathrm{hh}}+\hat{B}_{\mathrm{vv}}+2 \operatorname{Re}\left(\hat{B}_{\mathrm{hv}}\right)},
\end{aligned}
$$

$\hat{\rho}_{\mathrm{CX}}=$

$$
\frac{\left|\hat{B}_{\mathrm{hh}}-\hat{B}_{\mathrm{vv}}+2 i \operatorname{Im}\left(\hat{B}_{\mathrm{hv}}\right)\right|}{\sqrt{\left[\hat{B}_{\mathrm{hh}}+\hat{B}_{\mathrm{vv}}-2 \operatorname{Re}\left(\hat{B}_{\mathrm{hv}}\right)\right]\left[\hat{B}_{\mathrm{hh}}+\hat{B}_{\mathrm{vv}}+2 \operatorname{Re}\left(\hat{B}_{\mathrm{hv}}\right)\right]}} .
$$

\subsection{Retrieval technique}

Melnikov and Straka (2013) proposed a shape and orientation retrieval algorithm based on $Z_{\mathrm{DR}}$ and $\rho_{\mathrm{HV}}$ observed by a weather radar. The authors showed that the algorithm is applicable for cloud areas with $Z_{\mathrm{DR}}>4 \mathrm{~dB}$ where the backscatter signal is dominated by oblate particles. When $Z_{\mathrm{DR}}<4 \mathrm{~dB}$ the algorithm can not distinguish between oblate and prolate particles.

Matrosov (1991a) and Matrosov et al. (2012) showed that an appropriate classification of ice particles in clouds requires scanning in the elevation angle. Therefore, the shape and orientation retrieval, described below, requires measured elevation scans of differential reflectivity and correlation coefficient. We use scans in the elevation from -60 to $60^{\circ}\left(0^{\circ}\right.$ corresponds to the zenith pointing). Thus, from every scan cycle, two half-scans are obtained for the shape classification.

Using Eqs. (70)-(73) look-up tables of $\hat{Z}_{\mathrm{DR}}\left(\rho_{a}, \psi, \rho_{e}\right)$, $\hat{\rho}_{\mathrm{HV}}\left(\rho_{a}, \psi, \rho_{e}\right), \widehat{\operatorname{SLDR}}\left(\rho_{a}, \psi, \rho_{e}\right)$, and $\hat{\rho}_{\mathrm{CX}}\left(\rho_{a}, \psi, \rho_{e}\right)$ can be calculated. We use values from -1 to 1 for $\rho_{a}$, from -60 to $60^{\circ}$ for $\psi$, and from 0.3 to 2.3 for $\rho_{e}$. The chosen range of $\rho_{e}$ covers the possible values for ice shown in Fig. 10. The cross sections of modeled polarimetric variables for elevation angles 0 and $60^{\circ}$ are presented in Fig. 13. Left and right columns in Fig. 13 represent elevation angles $\psi$ of 60 and $0^{\circ}$, respectively. Values of $\rho_{a}=-1$ (upper part of diagrams) characterize particles with horizontally oriented symmetry axis; $\rho_{a}=0$ is typical for uniformly distributed orientation angles $\theta ; \rho_{a}=1$ (lower part of diagrams) describes a vertically oriented symmetry axis of particles. It should be noticed that $\rho_{a} \sim-0.4$ specifies the so-called fully chaotic orientation of particles (Ryzhkov, 2001) which can be considered as a special case of reflection symmetry (Nghiem et al., 1992). In this case the polarimetric variables do not depend on $\psi$, and $Z_{\mathrm{DR}}$ and $\rho_{\mathrm{CX}}$ are $0 \mathrm{~dB}$ and 0 , respectively. Values of $\rho_{e}<1$ designate oblate particles; $\rho_{e}=1$ represents spherical particles or particles with low density; $\rho_{e}>1$ corresponds to prolate particles.

In Fig. 13a $Z_{\mathrm{DR}}$ is larger than $0 \mathrm{~dB}$ in the lower left and in the upper right corners of the diagram. These corners correspond to horizontally aligned oblate and prolate particles, respectively. In contrast, in the upper left and in the lower right corners, particles are oriented vertically and thus produce $Z_{\mathrm{DR}}$ lower than $0 \mathrm{~dB}$. Additionally, oblate particles can produce larger $Z_{\mathrm{DR}}$ than prolate ones, in consistency with Hogan et al. (2002) and Melnikov and Straka (2013). For zenith pointing (Fig. 13b) $Z_{\mathrm{DR}}$ values are $0 \mathrm{~dB}$ because of the reflection symmetry (Nghiem et al., 1992). Figure 13c and $\mathrm{d}$ show that $\hat{\rho}_{\mathrm{HV}}$ is equal to 1 for spherical and horizontally aligned oblate particles. At $\psi=60^{\circ}$ values of $\hat{\rho}_{\mathrm{HV}}$ decrease with decreasing $\left|\rho_{a}\right|$. This behavior is especially noticeable for particles with $\rho_{e}<0.5$ and $\rho_{e}>1.8$. The relation between $\hat{\rho}_{\mathrm{HV}}$ and $\left|\rho_{a}\right|$ is consistent with the findings of Matrosov (1991b). Figure 13e shows that values of $\widehat{\text { SLDR }}$ are dominated by $\rho_{e}$ and only slightly depend on $\rho_{a}$. This feature was previously described in Reinking et al. (2002) and Matrosov et al. (2012). Galletti and Zrnic (2012) showed that in hybrid mode at the zenith pointing $\hat{\rho}_{\mathrm{HV}}$ is equal to the degree of polarization. In this case $\widehat{\mathrm{SLDR}}$ and $\hat{\rho}_{\mathrm{HV}}$ can be related as follows:

$\hat{\rho}_{\mathrm{HV}} \sim 1-2 \widehat{\mathrm{SLDR}}$.

The relation given by Eq. (74) can be clearly seen in Fig. $13 \mathrm{~d}$ and f. Figure $13 \mathrm{~g}$ shows that $\hat{\rho}_{\mathrm{CX}}$ is mostly defined by $\rho_{a}$, i.e., by the orientation of particles. This was previously found by Ryzhkov et al. (2002). For spherical particles $\left(\rho_{e}=1\right)$ we use the limit approximation $\hat{\rho}_{\mathrm{CX}}=0$ (Myagkov et al., 2015). As mentioned above $\hat{\rho}_{\mathrm{CX}}$ is equal to 0 in the case of reflection symmetry, i.e., when $\psi=0^{\circ}$ (Fig. 13h).

In this paper we consider the retrieval based on $Z_{\mathrm{DR}}$ and $\rho_{\mathrm{HV}}$ only. Nevertheless, the same approach can be applied to SLDR and $\rho_{\mathrm{CX}}$ that can be measured directly by cloud radars operating in the SLDR mode.

It is known that the Doppler velocity measured by a cloud radar is defined not only by the terminal velocity of particles, but also by air motion. Thus, Doppler spectra measured at different elevation angles usually have different shapes and mean values. In the following, we however have to assume that the maximums of spectra (spectrum peak), measured at a certain altitude and at different elevation angles, correspond to particles of similar microphysical properties.

Due to the spatial inhomogeneity of a cloud or in the case of a low SNR, some data points in a half-scan can be missing. Also some altitudes cannot be reached by the radar at 

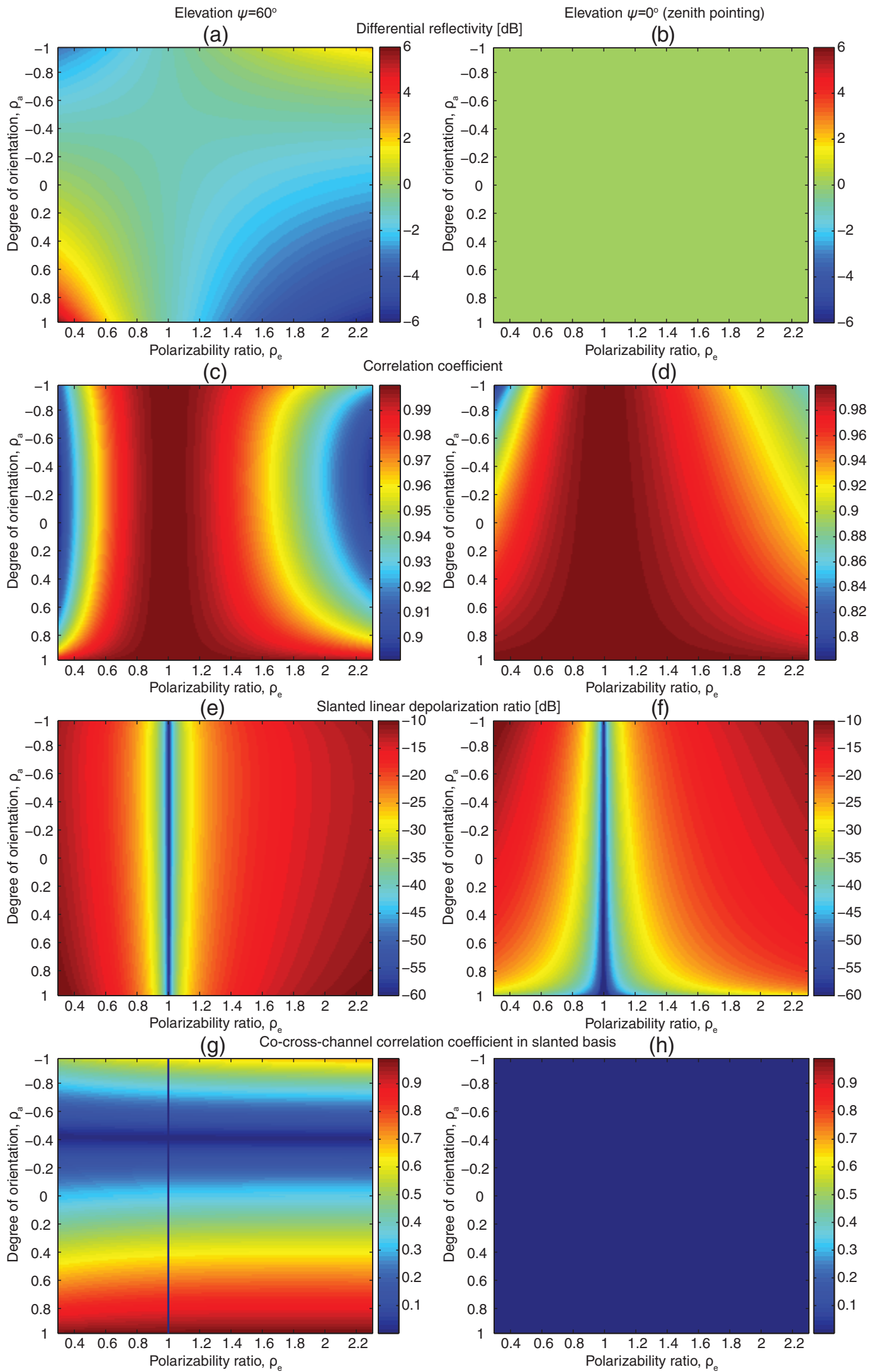

Figure 13. Modeled differential reflectivity $\hat{Z}_{\mathrm{DR}}(\mathbf{a}$ and $\mathbf{b})$, correlation coefficient $\hat{\rho}_{\mathrm{HV}}(\mathbf{c}$ and $\mathbf{d})$, slanted linear depolarization ratio $\widehat{\text { SLDR }}$ (e and $\mathbf{f})$, and co-cross-channel correlation coefficient in the slanted basis $\hat{\rho}_{\mathrm{CX}}(\mathbf{g}$ and $\mathbf{h})$. 
certain elevation angles. Therefore, we apply the algorithm only to the altitudes where more than $50 \%$ of data points of polarimetric variables in a half-scan are present.

For simplicity, we describe the retrieval for one altitude only. We use denotations $Z_{\mathrm{DR}}(\psi)$ and $\rho_{\mathrm{HV}}(\psi)$ which correspond to differential reflectivity and correlation coefficient, calculated for the maximum spectral line at the elevation angle $\psi$, respectively.

Using the scans of polarimetric variables and the look-up tables we calculate the following error functions:

$$
\begin{aligned}
& E_{\mathrm{ZDR}}\left(\rho_{a}, \rho_{e}\right)=\int_{\Psi}\left|Z_{\mathrm{DR}}(\psi)-\hat{Z}_{\mathrm{DR}}\left(\rho_{a}, \psi, \rho_{e}\right)\right|^{2} \mathrm{~d} \psi, \\
& E_{\mathrm{RHV}}\left(\rho_{a}, \rho_{e}\right)=\int_{\Psi}\left|\rho_{\mathrm{HV}}(\psi)-\hat{\rho}_{\mathrm{HV}}\left(\rho_{a}, \psi, \rho_{e}\right)\right|^{2} \mathrm{~d} \psi,
\end{aligned}
$$

where $\Psi$ represents elevation angles $\psi$ for a certain halfscan.

In order to classify particles as either prolate or oblate we search for the minimum of $E_{\mathrm{ZDR}}\left(\rho_{a}, \rho_{e}\right)$. We define values of $\rho_{a}$ and $\rho_{e}$, with corresponding $E_{\mathrm{ZDR}}\left(\rho_{a}, \rho_{e}\right)$ that do not exceed the minimum $E_{\mathrm{ZDR}}$ by a factor of 1.1. For these values of $\rho_{a}$ and $\rho_{e}$ we determine the lowest value of $E_{\mathrm{RHV}}\left(\rho_{a}, \rho_{e}\right)$. In the case when the minimum of $E_{\mathrm{RHV}}$ corresponds to $\rho_{e} \leq$ 1 , particles are classified as oblate spheroids. Otherwise the particles are prolate spheroids. It should be noted that without the correction for the antenna coupling (see Sect. 2.5) the algorithm can not reliably discriminate spheroids with polarizability ratios in the range from 0.8 to 1.2 .

After the classification we determine $\rho_{e}$ and $\rho_{a}$ for every elevation angle within ranges from 30 to 60 and from -60 to $-30^{\circ}$. These ranges have been chosen considering that polarimetric variables do not allow for the reliable discrimination between different properties of particles at elevation angles close to the zenith. We calculate the following function:

$$
\begin{aligned}
E_{s}\left(\rho_{a}, \psi, \rho_{e}\right)= & \left|Z_{\mathrm{DR}}(\psi)-\hat{Z}_{\mathrm{DR}}\left(\rho_{a}, \psi, \rho_{e}\right)\right|^{2} \\
& +\left[10\left|\rho_{\mathrm{HV}}(\psi)-\hat{\rho}_{\mathrm{HV}}\left(\rho_{a}, \psi, \rho_{e}\right)\right|\right]^{2} .
\end{aligned}
$$

We have not optimized the weighting factor in Eq. (77). It was set to 10 considering that errors in $Z_{\mathrm{DR}}$ are about 1 order of magnitude higher than errors in $\rho_{\mathrm{HV}}$. For every elevation angle $\psi$ we find values of $\rho_{e}$ and $\rho_{a}$, corresponding to the minimum of the function $E_{s}\left(\rho_{a}, \psi, \rho_{e}\right)$. We emphasize that the retrieval allows for the estimation of the polarizability ratio $\rho_{e}$. The estimation of the exact axis ratio $\rho_{g}$ from $\rho_{e}$ requires knowledge of density of ice crystals which has to be assumed or measured.

\section{Case study}

In this section we present a case study to demonstrate the applicability of MIRA-35 with hybrid mode for the particle

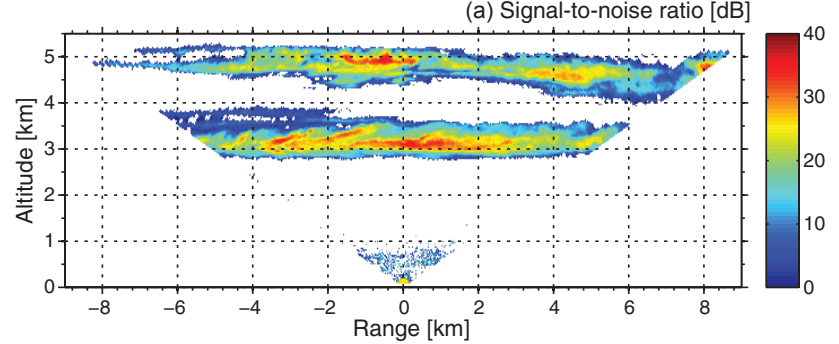

(b) Differential reflectivity $[\mathrm{dB}]$

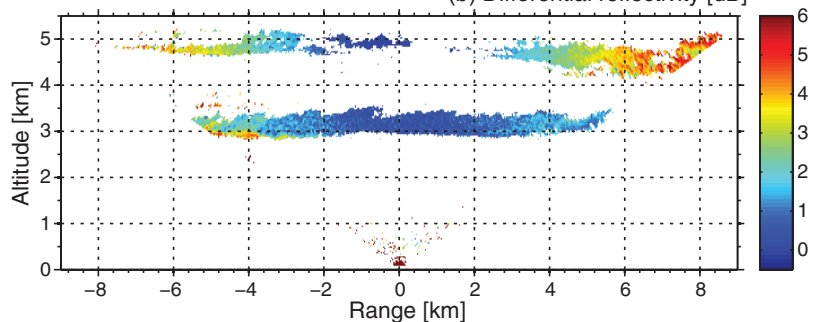

(c) Correlation coefficient

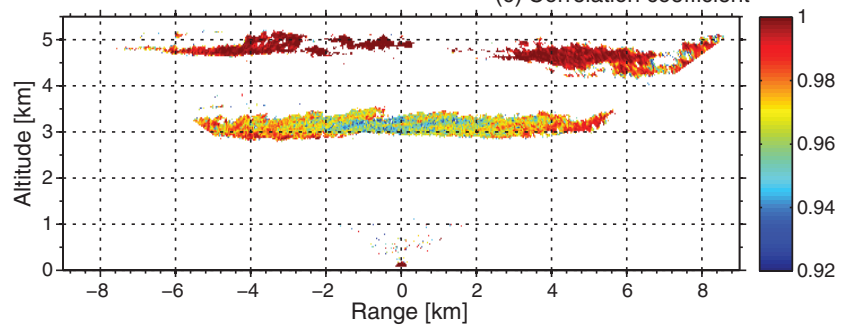

Figure 14. Range-altitude cross sections of (a) signal-to-noise ratio, (b) differential reflectivity $Z_{\mathrm{DR}}$, and (c) correlation coefficient $\rho_{\mathrm{HV}}$, taken at Cabauw, the Netherlands, from 18:16 to 18:20 UTC on 20 October 2014. Shown parameters are calculated for the maximum spectral lines (spectral peaks).

classification technique described above. The data set was acquired during the ACCEPT (Analysis of the Composition of Clouds with Extended Polarization Techniques) campaign which was conducted at Cabauw, the Netherlands, in October and November 2014.

Throughout the ACCEPT campaign the radar was operated with the number of averaged spectra $N_{\mathrm{s}}=20$ which corresponds to an averaging time of $1 \mathrm{~s}$. Within every $15 \mathrm{~min}$ the radar performed two elevation scans from -60 to $60^{\circ}$ at an angular speed of $0.5^{\circ} \mathrm{s}^{-1}$. One half scan between \pm 60 and $0^{\circ}$ was thus performed within $120 \mathrm{~s}$. The two scans were conducted perpendicular to each other in azimuth direction.

In Fig. 14 range-altitude cross sections of SNR, differential reflectivity, and correlation coefficient calculated for the maximum spectral lines are shown. These observations were taken in one azimuth plane on 20 October 2014 from 18:16 to 18:20 UTC. Two cloud layers at 2.7-3.5 and 4-5.2 km height are visible. We denote these layers as 1 and 2, respectively. Between the layers a clear gap is present, thus seeding of ice crystals from the upper layer into the lower layer (Rutledge and Hobbs, 1984) can be assumed to be absent. Temperatures at the tops of layers 1 and 2 derived with a collocated 
microwave radiometer HATPRO were about -6 and $-14{ }^{\circ} \mathrm{C}$, respectively.

In Figs. 15 and 16 a detailed analysis of the case introduced in Fig. 14 is presented for altitudes of 3 and $4.7 \mathrm{~km}$ (layer 1 and 2), respectively. Well-pronounced elevation dependencies in the differential reflectivity can be seen for both layers. At elevation angles of $|\psi|=60^{\circ}$ the differential reflectivity reaches values of $\sim 3$ and $\sim 5 \mathrm{~dB}$ for the layers 1 and 2 , respectively. In vertical pointing direction $(\psi=0)$ the differential reflectivity is close to 0.5 and $0 \mathrm{~dB}$, respectively. Thus, for both layers the differential reflectivity has its minimal value at $0^{\circ}$ elevation and increases at higher $|\psi|$.

In contrast to the differential reflectivity, the elevation dependencies of the correlation coefficient have different behavior for layers 1 and 2 (Figs. 15b and 16b). In layer $1 \rho_{\mathrm{HV}}$ has its minimum at $|\psi|=0^{\circ}$ whereas it shows increased values at higher $|\psi|$. In layer $2 \rho_{\mathrm{HV}}$ has a maximum at $|\psi|=0^{\circ}$ while at higher $|\psi|$ the values of $\rho_{\mathrm{HV}}$ are slightly lower.

Figures $15 \mathrm{c}, \mathrm{d}$ and $16 \mathrm{c}$ and $\mathrm{d}$ show the error functions $E_{\mathrm{ZDR}}\left(\rho_{a}, \rho_{e}\right)$ and $E_{\mathrm{RHV}}\left(\rho_{a}, \rho_{e}\right)$, respectively. We use the algorithm described in the Sect. 3.2 to distinguish between oblate and prolate particles at a certain altitude. The polarizability ratio determined using Fig. $15 \mathrm{c}$ and $\mathrm{d}$ is $\sim 1.6$, while the one from Fig. $16 \mathrm{c}$ and $\mathrm{d}$ is $\sim 0.4$. Thus, the spheroid types of the ice particles observed in layer $1(3 \mathrm{~km})$ and $2(4.7 \mathrm{~km})$ are classified as prolate and oblate, respectively.

After the classification of the spheroid type we obtain the polarizability ratio $\rho_{e}$ and the degree of orientation $\rho_{a}$ for every elevation angle in the following range: $30^{\circ} \leq|\psi| \leq 60^{\circ}$. Using the obtained values we calculate mean and standard deviation of $\rho_{e}$ and $\rho_{a}$ for every altitude. In order to estimate the influence of uncertainties in $Z_{\mathrm{DR}}$ and $\rho_{\mathrm{HV}}$ on the retrieval of $\rho_{e}$, we applied the algorithm to the measurements in light rain on 7 November 2015, from 20:30 to 21:00 UTC. The precipitation intensity during the chosen time period was about $1 \mathrm{~mm} \mathrm{~h}^{-1}$ as it was observed by a disdrometer on-site. We assume that raindrops have a spherical shape which is characterized by the polarizability ratio of 1 . Values of retrieved $\rho_{e}$ were mainly $1 \pm 0.02$.

We applied the algorithm to the polarimetric observations from 13:30 to 19:30 UTC of 20 October 2014. The results are presented in Fig. 17. Figure 17a shows the time-height cross section of the equivalent radar reflectivity factor from a collocated vertically pointed cloud radar MIRA-35 with LDR mode. The time period corresponding to the elevation scan that is shown in Fig. 14 is indicated by the red rectangle in Fig. 17a. Several cloud layers at different heights were observed during the measurement. High-level clouds with a cloud top at around $8 \mathrm{~km}$ height were observed from 13:30 to $14: 30$ UTC and $15: 00$ to $17: 00$ UTC. Reflectivity values for these cloud layers mostly exceeded $-10 \mathrm{dBZ}$ which is high enough to calculate polarimetric variables. From 15:00 to 20:00 UTC a thick mid-level cloud with a top at $5 \mathrm{~km}$ height was observed. At 16:40 UTC strong ice formation, indicated by high values of the radar reflectivity, was ob- served. Melting of ice particles resulted in a short precipitation event reaching the ground. Later the cloud experienced seeding from the high-level cloud above. After 18:15 UTC the cloud split into two thin cloud layers with cloud tops at 5 and $3 \mathrm{~km}$ height. Different ambient conditions within these layers caused, as it will be shown below, different types of ice crystals. At about $2 \mathrm{~km}$ height thin low-level cloud layers appeared from 13:00 to 17:00 UTC. These cloud layers did not have a large enough SNR and/or were spatially inhomogeneous and, therefore, were filtered out by the retrieval algorithm.

In Fig. 17b and c mean and standard deviation of the polarizability ratio are presented. It can be seen that the high-level clouds (above $5 \mathrm{~km}$ height) are characterized by a polarizability ratio of $0.85 \pm 0.07$. According to Eqs. (39) and (40) this can be caused either by ice particles of quasi-spherical shape or of low density or both. Low density $\left(<0.1 \mathrm{~g} \mathrm{~cm}^{-3}\right)$ of ice particles in cirrus clouds was, e.g., reported by Heymsfield et al. (2002). Ice particles in the mid-level cloud with the top below $5 \mathrm{~km}$ height showed values of $\rho_{e} \approx 0.43 \pm 0.17$, which indicates a strongly oblate shape and a high density of ice particles (Fig. 10). From 15:50 to 16:30 UTC the polarizability ratio increased to values of $\rho_{e} \approx 0.83 \pm 0.1$ towards the bottom of the cloud. These signatures were accompanied by an enhancement of the effective radar reflectivity factor (Fig. 17a). Thus, the larger particles were more spherical and/or less dense, which is a clear indication of particle growth due to aggregation and/or riming processes. The capability to identify these processes can be especially useful for the investigation of precipitation formation. It can be seen in the virga shown in Fig. 17a, which partly reaches the ground, that the areas in which aggregation or riming occur can produce precipitation. From 18:15 to 19:15 UTC a thin cloud layer with prolate ice particles was observed at $3 \mathrm{~km}$ height. These particles are characterized by $\rho_{e} \approx 1.5 \pm 0.2$.

In Fig. 17d and e the mean and standard deviation of the degree of orientation are shown, respectively. Areas where the spheroid shape of the ice particles was classified as strongly oblate or prolate are characterized by $\left|\rho_{a}\right|$ values of $\sim 0.7$ and $\sim 0.95$, respectively, i.e., particles are oriented nearly horizontally which is consistent with theoretical studies (Sassen, 1980; Mitchell, 1996; Noel and Sassen, 2005). The low standard deviation of $\left|\rho_{a}\right|$ in these areas indicates that the orientation distributions for different populations of ice particles are similar. Observed high-level clouds and cloud areas with seeding had considerably lower values of the degree of orientation with $\left|\rho_{a}\right| \sim 0.4-0.6$. These values are indicative of a more random orientation of ice particles around the horizontal alignment. The high standard deviation of $\rho_{a}$ in these clouds can be explained by different orientation distributions of different populations of ice particles. 

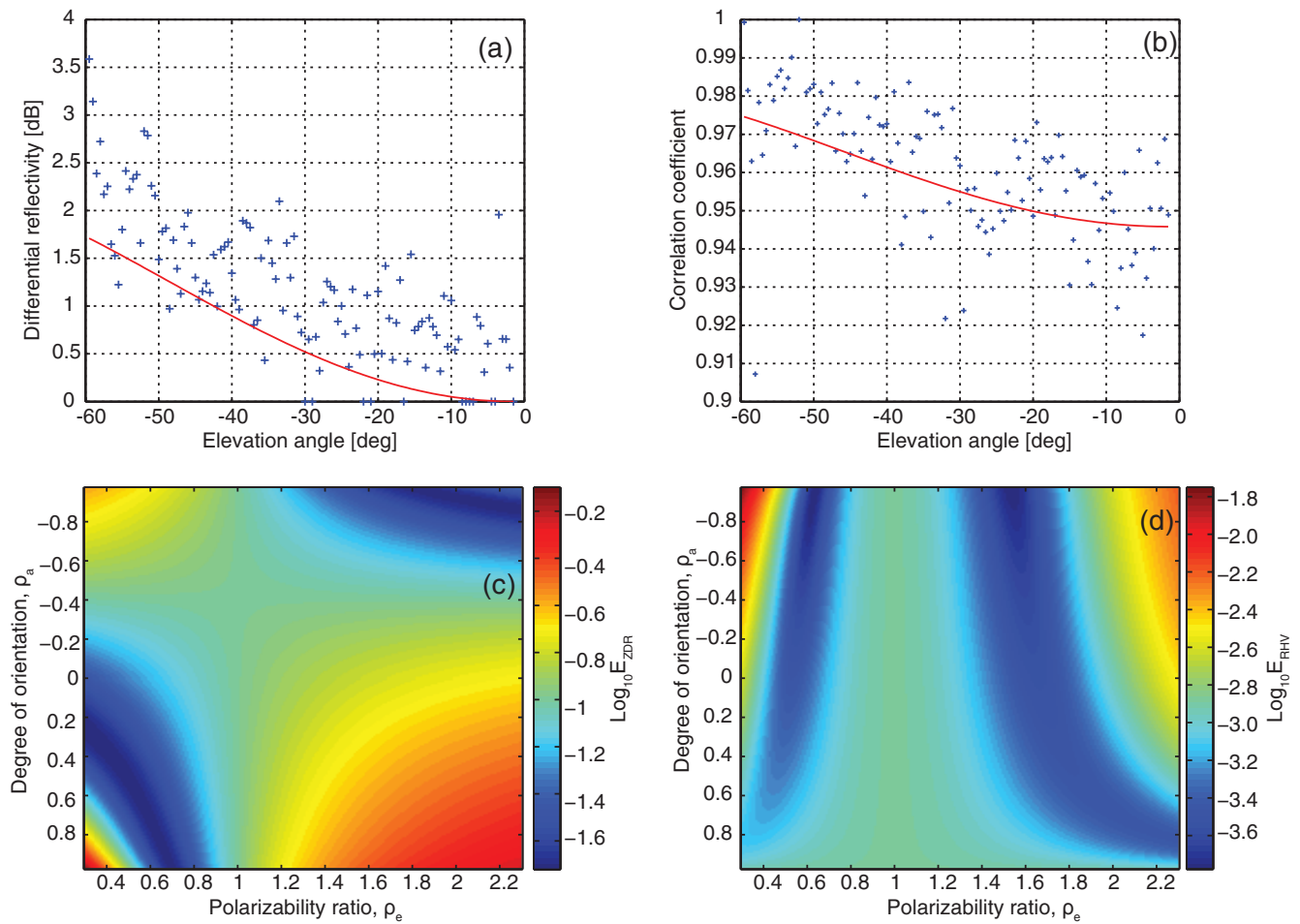

Figure 15. Measured (blue crosses) and approximated (red solid curve) elevation dependencies of differential reflectivity (a) and correlation coefficient (b), and logarithms of $E_{\mathrm{ZDR}}(\mathbf{c})$ and $E_{\mathrm{RHV}}(\mathbf{d})$. Measured data correspond to $3 \mathrm{~km}$ height of the left half-scan of Fig. 14. According to the classification scheme described in the text, this case corresponds to a polarizability ratio of 1.6 (prolate spheroids).
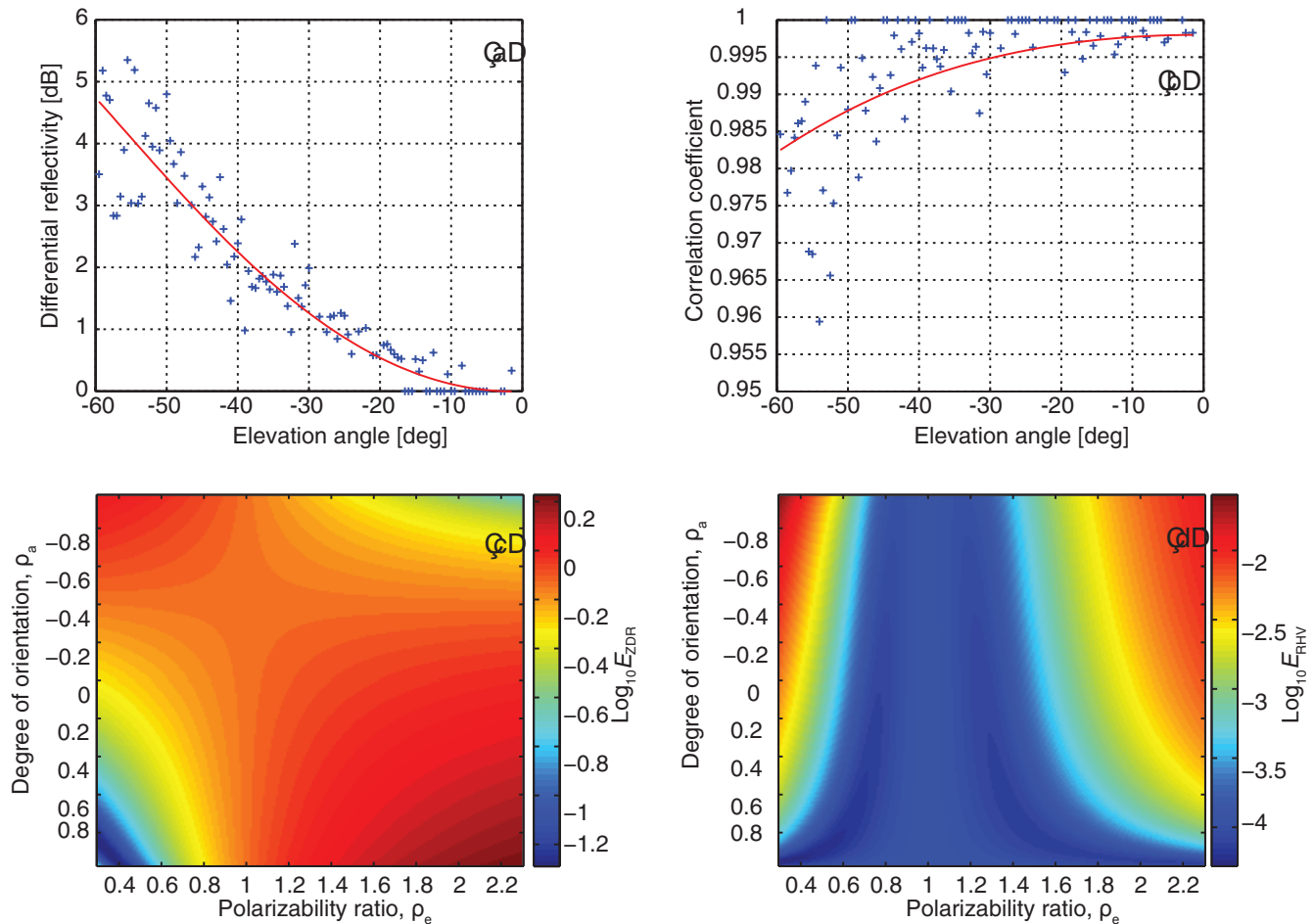

Figure 16. Measured (blue crosses) and approximated (red solid curve) elevation dependencies of differential reflectivity (a) and correlation coefficient (b), and logarithms of $E_{\mathrm{ZDR}}(\mathbf{c})$ and $E_{\mathrm{RHV}}(\mathbf{d})$. Measured data correspond to $4.7 \mathrm{~km}$ height of the left half-scan of Fig. 14 . According to the classification scheme described in the text, this case corresponds to a polarizability ratio of 0.4 (oblate spheroids). 

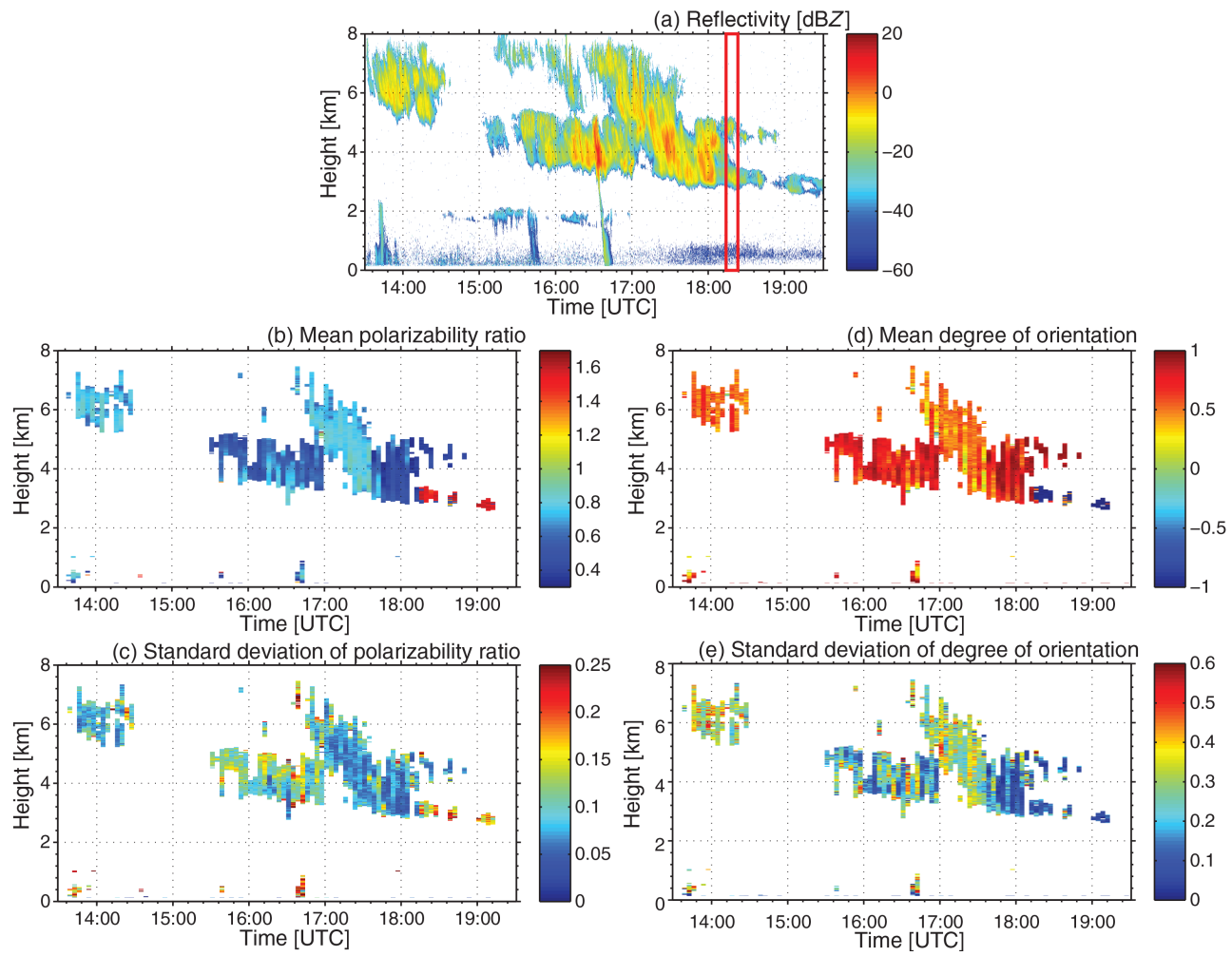

Figure 17. Height-time cross sections of (a) equivalent radar reflectivity factor $Z_{\mathrm{h}}$, the mean (b) and standard deviation (c) of polarizability ratio $\rho_{e}$, and the mean (d) and standard deviation (e) of degree of orientation $\rho_{a}$, taken at Cabauw, the Netherlands, on 20 October 2014 . The equivalent radar reflectivity factor $Z_{\mathrm{h}}$ was measured by a collocated vertically pointed $35 \mathrm{GHz}$ cloud radar MIRA-35 with LDR mode and with $1 \mathrm{~s}$ averaging. The red rectangle shows the time period which corresponds to Fig. 14.

\section{Summary and conclusion}

Existing backscattering models, assuming the spheroidal approximation of cloud scatterers, allow for the estimation of parameters (polarizability ratio and degree of orientation) connected with the shape and orientation of particles. Accurate measurement of these parameters by cloud radars requires a set of polarimetric variables.

In order to measure a variety of polarimetric variables, the new $35 \mathrm{GHz}$ cloud radar MIRA-35 with hybrid polarimetric configuration was implemented in collaboration between the Leibniz Institute for Tropospheric Research (TROPOS), Leipzig, Germany, and METEK GmbH, Elmshorn, Germany, within the Initial Training for atmospheric Remote Sensing (ITaRS) project. The radar emits the horizontal and vertical component of the transmitted wave simultaneously, with the differential phase shift set close to $0^{\circ}$. The polarization calibration of the radar was performed using an external test transmitter and vertical measurements in light rain. Additionally, the correction for the antenna coupling was applied. Vertical observations with the radar under rain conditions show the high accuracy of the polarization calibration.

The radar permits the measurement of spectral polarimetric parameters: differential reflectivity, slanted linear depo- larization ratio, correlation coefficient, co-cross-channel correlation coefficient in the slanted basis, and differential phase shift. The slanted linear depolarization ratio and co-crosschannel correlation coefficient are derived using the rotation of the measured coherency matrix. Retrieved values of these parameters are consistent with observations of cloud radars with the LDR or SLDR mode. The algorithm for deriving the polarizability ratio and degree of orientation of particles based on the differential reflectivity and correlation coefficient was developed. The same approach can be applied to the slanted linear depolarization ratio and co-cross-channel correlation coefficient. It should be noted that the retrieval of ice particle shape from the measured polarizability ratio additionally requires the information about the density of ice particles.

The algorithm was applied to observations made during the ACCEPT campaign in Cabauw, the Netherlands, where the new cloud radar was deployed in October and November 2014. Vertical profiles of the polarizability ratio and the degree of orientation were retrieved. The results show clouds with oblate $\left(\rho_{e} \approx 0.43 \pm 0.17\right)$, prolate $\left(\rho_{e} \approx 1.5 \pm 0.2\right)$, and quasi-spherical or low-density particles $\left(\rho_{e} \approx 0.85 \pm 0.07\right)$. All these clouds had different cloud top heights $(5,3$, and $8 \mathrm{~km}$, respectively), indicating different ambient conditions 
of ice formation. Areas in which aggregation and/or riming led to ice particle growth could be detected. High absolute values of the degree of orientation observed in areas dominated by oblate and prolate ice particles indicated their nearly horizontal orientation. Orientation of slightly oblate or lowdensity ice particles, detected in high-level clouds and in areas with seeding, was found to be more random, though the primary orientation was horizontal.

In conclusion, the proposed algorithm provides valuable information about the shape and orientation of ice crystals which is especially important for the investigation of midlevel mixed-phase clouds. The retrieved vertical profiles of $\rho_{e}$ allow the change in the shape and orientation of ice crystals to be tracked. Combined analysis of these profiles and Doppler spectra of vertical velocity can be used for studies of size-shape-terminal velocity relations of particles in the atmosphere. Tyynelä and Chandrasekar (2014) recently showed a potential of combining the polarimetric and multifrequency approaches. Therefore, a synergistic use of the proposed algorithm and multi-frequency analysis can yield additional information.

Acknowledgements. The research leading to these results has received funding from the European Union Seventh Framework Programme (FP7/2007-2013): People, ITN Marie Curie Actions Programme (2012-2016) in the frame of ITaRS under grant agreement no. 289923. The ACCEPT campaign was partly funded by the European Union Seventh Framework Programme (FP7/2007-2013) under grant agreement no. 262254.

Edited by: M. Kulie

\section{References}

Born, M. and Wolf, E.: Principles of Optics, Pergamon Press, Oxford, 1975.

Bringi, V. N. and Chandrasekar, V.: Polarimetric Doppler Weather Radar, Cambridge University Press, Cambridge, UK, 662 pp., 2001.

Bühl, J., Ansmann, A., Seifert, P., Baars, H., and Engelmann, R.: Toward a quantitative characterization of heterogeneous ice formation with lidar/radar: comparison of CALIPSO/CloudSat with ground-based observations, Geophys. Res. Lett., 40, 4404-4408, doi:10.1002/grl.50792, 2013.

Chandrasekar, V. and Keeler, R. J.: Antenna pattern analysis and measurements for multiparameter radars, J. Atmos. Ocean. Tech., 10, 674-683, doi:10.1175/15200426(1993)010<0674:APAAMF>2.0.CO;2, 1993.

De Boer, G., Eloranta, E. W., and Shupe, M. D.: Arctic mixed-phase stratiform cloud properties from multiple years of surface-based measurements at two high-latitude locations, J. Atmos. Sci., 66, 2874-2887, doi:10.1175/2009JAS3029.1, 2009.

Delanoë, J. and Hogan, R. J.: Combined CloudSat-CALIPSOMODIS retrievals of the properties of ice clouds, J. Geophys. Res.-Atmos., 115, D00H29, doi:10.1029/2009JD012346, 2010.
Delanoë, J. M. E., Heymsfield, A. J., Protat, A., Bansemer, A., and Hogan, R. J.: Normalized particle size distribution for remote sensing application, J. Geophys. Res.-Atmos., 119, 4204-4227, doi:10.1002/2013JD020700, 2014.

DeMott, P. J., Prenni, A. J., McMeeking, G. R., Sullivan, R. C., Petters, M. D., Tobo, Y., Niemand, M., Möhler, O., Snider, J. R., Wang, Z., and Kreidenweis, S. M.: Integrating laboratory and field data to quantify the immersion freezing ice nucleation activity of mineral dust particles, Atmos. Chem. Phys., 15, 393-409, doi:10.5194/acp-15-393-2015, 2015.

Di Girolamo, P., Summa, D., Cacciani, M., Norton, E. G., Peters, G., and Dufournet, Y.: Lidar and radar measurements of the melting layer: observations of dark and bright band phenomena, Atmos. Chem. Phys., 12, 4143-4157, doi:10.5194/acp-12-41432012, 2012.

Galletti, M. and Zrnic, D. S.: Degree of polarization at simultaneous transmit: theoretical aspects, IEEE Geosci. Remote S., 9, 383387, doi:10.1109/LGRS.2011.2170150, 2012.

Galloway, J., Pazmany, A., Mead, J., McIntosh, R. E., Leon, D., French, J., Kelly, R., and Vali, G.: Detection of ice hydrometeor alignment using an airborne W-band polarimetric radar, J. Atmos. Ocean. Tech., 14, 3-12, doi:10.1175/15200426(1997)014<0003:DOIHAU>2.0.CO;2, 1997.

Görsdorf, U., Lehmann, V., Bauer-Pfundstein, M., Peters, G., Vavriv, D., Vinogradov, V., and Volkov, V.: A $35 \mathrm{GHz}$ polarimetric Doppler radar for long term observations of cloud parameters - description of system and data processing, J. Atmos. Ocean. Tech., 32, 675-690, doi:10.1175/JTECH-D-14-00066.1, 2015.

Hendry, A., McCormick, G. C., and Barge, B. L.: The degree of common orientation of hydrometeors observed by polarization diversity radars, J. Appl. Meteorol., 15, 633-640, doi:10.1175/1520-0450(1976)015<0633:TDOCOO>2.0.CO;2, 1976.

Heymsfield, A. J., Bansemer, A., Field, P. R., Durden, S. L., Stith, J. L., Dye, J. E., Hall, W., and Grainger, C. A.: Observations and parameterizations of particle size distributions in deep tropical cirrus and stratiform precipitating clouds: results from in situ observations in TRMM field campaigns, J. Atmos. Sci., 59, 3457-3491, doi:10.1175/15200469(2002)059<3457:OAPOPS>2.0.CO;2, 2002.

Hildebrand, P. H. and Sekhon, R. S.: Objective determination of the noise level in Doppler spectra, J. Appl. Meteorol., 13, 808-811, doi:10.1175/1520-0450(1974)013<0808:ODOTNL>2.0.CO;2, 1974.

Hogan, R. J., Field, P. R., Illingworth, A. J., Cotton, R. J., and Choularton, T. W.: Properties of embedded convection in warm-frontal mixed-phase cloud from aircraft and polarimetric radar, Q. J. Roy. Meteor. Soc., 128, 451-476, doi:10.1256/003590002321042054, 2002.

Holt, A. R.: Some factors affecting the remote sensing of rain by polarization diversity radar in the 3 - to $35 \mathrm{GHz}$ frequency range, Radio Sci., 19, 1399-1412, doi:10.1029/RS019i005p01399, 1984.

Hoose, C. and Möhler, O.: Heterogeneous ice nucleation on atmospheric aerosols: a review of results from laboratory experiments, Atmos. Chem. Phys., 12, 9817-9854, doi:10.5194/acp-12-98172012, 2012.

Illingworth, A. J., Hogan, R. J., O’Connor, E. J., Bouniol, D., Delanoë, J., Pelon, J., Protat, A., Brooks, M. E., Gaussiat, N., Wilson, D. R., Donovan, D. P., Baltink, H. K., van Zadelhoff, G.- 
J., Eastment, J. D., Goddard, J. W. F., Wrench, C. L., Haeffelin, M., Krasnov, O. A., Russchenberg, H. W. J., Piriou, J.-M., Vinit, F., Seifert, A., Tompkins, A. M., and Willén, U.: Cloudnet, B. Am. Meteorol. Soc., 88, 883-898, doi:10.1175/BAMS-88-6$883,2007$.

Kanareykin, D. B., Pavlov, N. F., and Potechin, V. A.: Polarization of Radar Signals, Sov. radio, Moscow, USSR, 440 pp., 1966 (in Russian).

Kneifel, S., Kulie, M. S., and Bennartz, R.: A triple-frequency approach to retrieve microphysical snowfall parameters, J. Geophys. Res.-Atmos., 116, D11203, doi:10.1029/2010JD015430, 2011.

Kneifel, S., von Lerber, A., Tiira, J., Moisseev, D., Kollias, P., and Leinonen, J.: Observed relations between snowfall microphysics and triple-frequency radar measurements, J. Geophys. Res.Atmos., 120, 6034-6055, doi:10.1002/2015JD023156, 2015.

Ladino Moreno, L. A., Stetzer, O., and Lohmann, U.: Contact freezing: a review of experimental studies, Atmos. Chem. Phys., 13, 9745-9769, doi:10.5194/acp-13-9745-2013, 2013.

Lohmeier, S. P., Sekelsky, S. M., Firda, J. M., Sadowy, G. A., and McIntosh, R. E.: Classification of particles in stratiform clouds using the 33 and $95 \mathrm{GHz}$ polarimetric cloud profiling radar system (CPRS), IEEE T. Geosci. Remote, 35, 256-270, doi:10.1109/36.563264, 1997.

Löhnert, U., Schween, J. H., Acquistapace, C., Ebell, K., Maahn, M., Barrera-Verdejo, M., Hirsikko, A., Bohn, B., Knaps, A., O'Connor, E., Simmer, C., Wahner, A., and Crewell, S.: JOYCE: Jülich observatory for cloud evolution, B. Am. Meteorol. Soc., 96, 1157-1174, 2015.

Mace, G. G., Heymsfield, A. J., and Poellot, M. R.: On retrieving the microphysical properties of cirrus clouds using the moments of the millimeter-wavelength Doppler spectrum, J. Geophys. Res.Atmos., 107, 4815, doi:10.1029/2001JD001308, 2002.

Marcuvitz, M.: Waveguide Handbook, Dover Publications, Inc., New York, 428 pp., 1965.

Martucci, G. and O'Dowd, C. D.: Ground-based retrieval of continental and marine warm cloud microphysics, Atmos. Meas. Tech., 4, 2749-2765, doi:10.5194/amt-4-2749-2011, 2011.

Matrosov, S. Y.: Theoretical study of radar polarization parameters obtained from cirrus clouds, J. Atmos. Sci., 48, 1062-1070, doi:10.1175/1520-0469(1991)048<1062:TSORPP>2.0.CO;2, 1991a.

Matrosov, S. Y.: Prospects for the measurement of ice cloud particle shape and orientation with elliptically polarized radar signals, Radio Sci., 26, 847-856, doi:10.1029/91RS00965, 1991 b.

Matrosov, S. Y.: Evaluations of the spheroidal particle model for describing cloud radar depolarization ratios of ice hydrometeors, J. Atmos. Ocean. Tech., 32, 865-879, doi:10.1175/JTECH-D-1400115.1, 2015.

Matrosov, S. Y. and Kropfli, R. A.: Cirrus cloud studies with elliptically polarized Ka-band radar signals: a suggested approach, J. Atmos. Ocean. Tech., 10, 684-692, doi:10.1175/15200426(1993)010<0684:CCSWEP>2.0.CO;2, 1993.

Matrosov, S. Y., Kropfli, R. A., Reinking, R. F., and Martner, B. E.: Prospects for measuring rainfall using propagation differential phase in $\mathrm{X}$ - and $\mathrm{K}_{\mathrm{a}}$-radar bands, J. Appl. Meteorol., 38, 766-776, doi:10.1175/1520-0450(1999)038<0766:PFMRUP>2.0.CO;2, 1999.
Matrosov, S. Y., Reinking, R. F., Kropfli, R. A., Martner, B. E., and Bartram, B. W.: On the use of radar depolarization ratios for estimating shapes of ice hydrometeors in winter clouds, J. Appl. Meteorol., 40, 479-490, doi:10.1175/15200450(2001)040<0479:OTUORD>2.0.CO;2, 2001.

Matrosov, S. Y., Mace, G. G., Marchand, R., Shupe, M. D., Hallar, A. G., and McCubbin, I. B.: Observations of ice crystal habits with a scanning polarimetric W-band radar at slant linear depolarization ratio mode, J. Atmos. Ocean. Tech., 29, 989-1008, doi:10.1175/JTECH-D-11-00131.1, 2012.

Mech, M., Orlandi, E., Crewell, S., Ament, F., Hirsch, L., Hagen, M., Peters, G., and Stevens, B.: HAMP - the microwave package on the High Altitude and LOng range research aircraft (HALO), Atmos. Meas. Tech., 7, 4539-4553, doi:10.5194/amt7-4539-2014, 2014.

Melnikov, V. and Straka, J. M.: Axis ratios and flutter angles of cloud ice particles: retrievals from radar data, J. Atmos. Ocean. Tech., 30, 1691-1703, doi:10.1175/JTECH-D-12-00212.1, 2013.

Melnikov, V. M., Doviak, R. J., Zrnic, D. S., and Stensrud, D. J.: Mapping Bragg scatter with a polarimetric WSR-88D, J. Atmos. Ocean. Tech., 28, 1273-1285, doi:10.1175/JTECH-D-1005048.1, 2011.

Mitchell, D. L.: Use of mass- and area-dimensional power laws for determining precipitation particle terminal velocities, J. Atmos. Sci., 53, 1710-1723, doi:10.1175/15200469(1996)053<1710:UOMAAD>2.0.CO;2, 1996.

Mudukutore, A., Chandrasekar, V., and Mueller, E. A.: The differential phase pattern of the CSU CHILL radar antenna, J. Atmos. Ocean. Tech., 12, 1120-1123, doi:10.1175/15200426(1995)012<1120:TDPPOT>2.0.CO;2, 1995.

Murray, B. J., O'Sullivan, D., Atkinson, J. D., and Webb, M. E.: Ice nucleation by particles immersed in supercooled cloud droplets, Chem. Soc. Rev., 41, 6519-6554, doi:10.1039/C2CS35200A, 2012.

Myagkov, A., Seifert, P., Wandinger, U., Bauer-Pfundstein, M., and Matrosov, S. Y.: Effects of antenna patterns on cloud radar polarimetric measurements, J. Atmos. Ocean. Tech., 32, 1813-1828, doi:10.1175/JTECH-D-15-0045.1, 2015.

Nghiem, S. V., Yueh, S. H., Kwok, R., and Li, F. K.: Symmetry properties in polarimetric remote sensing, Radio Sci., 27, 693711, doi:10.1029/92RS01230, 1992.

Noel, V. and Sassen, K.: Study of planar ice crystal orientations in ice clouds from scanning polarization lidar observations, J. Appl. Meteorol., 44, 653-664, doi:10.1175/JAM2223.1, 2005.

Oguchi, T.: Electromagnetic wave propagation and scattering in rain and other hydrometeors, IEEE Proc., 71, 1029-1078, 1983.

Pazmany, A., Mead, J., McIntosh, R., Hervig, M., Kelly, R., and Vali, G.: $95 \mathrm{GHz}$ polarimetric radar measurements of orographic cap clouds, J. Atmos. Ocean. Tech., 11, 140-153, doi:10.1175/1520-0426(1994)011<0140:GPRMOO>2.0.CO;2, 1994.

Phillips, V. T. J., Demott, P. J., Andronache, C., Pratt, K. A., Prather, K. A., Subramanian, R., and Twohy, C.: Improvements to an empirical parameterization of heterogeneous ice nucleation and its comparison with observations, J. Atmos. Sci., 70, 378409, doi:10.1175/JAS-D-12-080.1, 2013.

Ray, P. S.: Broadband complex refractive indices of ice and water, Appl. Optics, 11, 1836-1844, doi:10.1364/AO.11.001836, 1972. 
Reinking, R. F., Matrosov, S. Y., Kropfli, R. A., and Bartram, B. W.: Evaluation of a $45 \mathrm{deg}$ slant quasi-linear radar polarization state for distinguishing drizzle droplets, pristine ice crystals, and less regular ice particles, J. Atmos. Ocean. Tech., 19, 296-321, doi:10.1175/1520-0426-19.3.296, 2002.

Rutledge, S. A. and Hobbs, P. V.: The Mesoscale and Microscale Structure and Organization of Clouds and Precipitation in Midlatitude Cyclones. XII: A Diagnostic Modeling Study of Precipitation Development in Narrow Cold-Frontal Rainbands, J. Atmos. Sci., 41, 2949-2972, doi:10.1175/15200469(1984)041<2949:TMAMSA>2.0.CO;2, 1984.

Ryzhkov, A. V.: Interpretation of polarimetric radar covariance matrix for meteorological scatterers: theoretical analysis, J. Atmos. Ocean. Tech., 18, 315-328, doi:10.1175/15200426(2001)018<0315:IOPRCM>2.0.CO;2, 2001.

Ryzhkov, A. V., Zrnic, D. S., Hubbert, J. C., Bringi, V. N., Vivekanandan, J., and Brandes, E. A.: Polarimetric radar observations and interpretation of co-cross-polar correlation coefficients, J. Atmos. Ocean. Tech., 19, 340-354, doi:10.1175/15200426-19.3.340, 2002.

Ryzhkov, A. V., Schuur, T. J., Burgess, D. W., Heinselman, P. L., Giangrande, S. E., and Zrnic, D. S.: The joint polarization experiment: polarimetric rainfall measurements and hydrometeor classification, B. Am. Meteorol. Soc., 86, 809-824, doi:10.1175/BAMS-86-6-809, 2005.

Sassen, K.: Remote sensing of planar ice crystal fall attitudes, J. Meteorol. Soc. Jpn., 58, 422-429, 1980.

Shupe, M. D., Daniel, J. S., de Boer, G., Eloranta, E. W., Kollias, P., Long, C. N., Luke, E. P., Turner, D. D., and Verlinde, J.: A focus on mixed-phase clouds, B. Am. Meteorol. Soc., 89, 1549-1562, doi:10.1175/2008BAMS2378.1, 2008.

Skolnik, M.: Introduction to Radar Systems, McGraw-Hill, New York, 1980.
Spek, A. L. J., Unal, C. M. H., Moisseev, D. N., Russchenberg, H. W. J., Chandrasekar, V., and Dufournet, Y.: A new technique to categorize and retrieve the microphysical properties of ice particles above the melting layer using radar dualpolarization spectral analysis, J. Atmos. Ocean. Tech., 25, 482497, doi:10.1175/2007JTECHA944.1, 2008.

Stephens, G. L., Vane, D. G., Tanelli, S., Im, E., Durden, S., Rokey, M., Reinke, D., Partain, P., Mace, G. G., Austin, R., L'Ecuyer, T., Haynes, J., Lebsock, M., Suzuki, K., Waliser, D., Wu, D., Kay, J., Gettelman, A., Wang, Z., and Marchand, R.: CloudSat mission: Performance and early science after the first year of operation, J. Geophys. Res.-Atmos., 113, d00A18, doi:10.1029/2008JD009982, 2008.

Trömel, S., Kumjian, M. R., Ryzhkov, A. V., Simmer, C., and Diederich, M.: Backscatter differential phase-estimation and variability, J. Appl. Meteorol. Clim., 52, 2529-2548, doi:10.1175/JAMC-D-13-0124.1, 2013.

Tyynelä, J. and Chandrasekar, V.: Characterizing falling snow using multifrequency dual-polarization measurements, J. Geophys. Res.-Atmos., 119, 8268-8283, doi:10.1002/2013JD021369, 2014.

Wang, Y., Chandrasekar, V., and Bringi, V. N.: Characterization and evaluation of hybrid polarization observation of precipitation, J. Atmos. Ocean. Tech., 23, 552-572, doi:10.1175/JTECH1869.1, 2006.

Westbrook, C. D. and Heymsfield, A. J.: Ice crystals growing from vapor in supercooled clouds between -2.5 and $-22^{\circ} \mathrm{C}$ : testing current parameterization methods using laboratory data, J. Atmos. Sci., 68, 2416-2429, doi:10.1175/JAS-D-11-017.1, 2011.

Wolde, M. and Vali, G.: Polarimetric signatures from ice crystals observed at $95 \mathrm{GHz}$ in winter clouds. Part I: Dependence on crystal form, J. Atmos. Sci., 58, 828-841, doi:10.1175/15200469(2001)058<0828:PSFICO>2.0.CO;2, 2001. 